\title{
Effects of metal cation substitution on hexavalent chromium reduction by green rust
}

\author{
Andrew N. Thomas ${ }^{1 *}$ (D) Elisabeth Eiche ${ }^{1}$, Jörg Göttlicher², Ralph Steininger² , Liane G. Benning ${ }^{3,4}$, \\ Helen M. Freemann ${ }^{3,7}$, Dominique J. Tobler ${ }^{5}$, Marco Mangayayam ${ }^{5}$, Knud Dideriksen ${ }^{5}$ and Thomas Neumann ${ }^{6}$
}

\begin{abstract}
Chromium contamination is a serious environmental issue in areas affected by leather tanning and metal plating, and green rust sulfate has been tested extensively as a potential material for in situ chemical reduction of hexavalent chromium in groundwater. Reported products and mechanisms for the reaction have varied, most likely because of green rust's layered structure, as reduction at outer and interlayer surfaces might produce different reaction products with variable stabilities. Based on studies of $\mathrm{Cr}$ (III) oxidation by biogenic Mn (IV) oxides, Cr mobility in oxic soils is controlled by the solubility of the $\mathrm{Cr}(\mathrm{III})$-bearing phase. Therefore, careful engineering of green rust properties, i.e., crystal/particle size, morphology, structure, and electron availability, is essential for its optimization as a remediation reagent. In the present study, pure green rust sulfate and green rust sulfate with $\mathrm{Al}, \mathrm{Mg}$ and $\mathrm{Zn}$ substitutions were synthesized and reacted with identical chromate $\left(\mathrm{CrO}_{4}{ }^{2-}\right)$ solutions. The reaction products were characterized by $\mathrm{X}$-ray diffraction, pair distribution function analysis, $\mathrm{X}$-ray absorption spectroscopy and transmission electron microscopy and treated with synthetic $\delta-\mathrm{MnO}_{2}$ to assess how easily $\mathrm{Cr}(\mathrm{III})$ in the products could be oxidized. It was found that $\mathrm{Mg}$ substitution had the most beneficial effect on $\mathrm{Cr}$ lability in the product. Less than $2.5 \%$ of the $\mathrm{Cr}(\mathrm{III})$ present in the reacted Mg-GR was reoxidized by $\delta-\mathrm{MnO}_{2}$ within 14 days, and the particle structure and $\mathrm{Cr}$ speciation observed during $\mathrm{X}$-ray scattering and absorption analyses of this product suggested that $\mathrm{Cr}(\mathrm{VI})$ was reduced in its interlayer. Reduction in the interlayer lead to the linkage of newly-formed $\mathrm{Cr}$ (III) to hydroxyl groups in the adjacent octahedral layers, which resulted in increased structural coherency between these layers, distinctive rim domains, sequestration of $\mathrm{Cr}($ III) in insoluble Fe oxide bonding environments resistant to reoxidation and partial transformation to $\mathrm{Cr}(\mathrm{III})$-substituted feroxyhyte. Based on the results of this study of hexavalent chromium reduction by green rust sulfate and other studies, further improvements can also be made to this remediation technique by reacting chromate with a large excess of green rust sulfate, which provides excess Fe(II) that can catalyze transformation to more crystalline iron oxides, and synthesis of the reactant under alkaline conditions, which has been shown to favor chromium reduction in the interlayer of Fe(II)bearing phyllosilicates.
\end{abstract}

Keywords: Chromium, Green rust, X-ray absorption spectroscopy, Remediation

*Correspondence: andrew.thomas@kit.edu

${ }^{1}$ Institute of Applied Geosciences, Karlsruhe Institute of Technology, 76137 Karlsruhe, Germany

Full list of author information is available at the end of the article

\section{Introduction}

Chromium is a common groundwater contaminant suitable for remediation by in situ chemical reduction $[1,2]$. Geogenic chromium is associated with surficial ultramafic outcroppings, while anthropogenic chromium contamination typically results from chromium mining, metal plating facilities, tanneries and wood and 
paper treatment plants [3]. Once chromium enters soil and groundwater, its solubility and toxicity depend on its chemical speciation. In its trivalent form, chromium is insoluble and non-toxic, and is even an essential trace metal for sugar metabolism [4]. However, in its hexavalent oxidation state, chromium takes the form of chromate $\left(\mathrm{CrO}_{4}{ }^{2-}\right)$, a highly soluble, toxic and carcinogenic compound. Redox transformations between the two forms occur in response to changing redox conditions; these transformations are often mediated by other metal biogeochemical cycles. $\mathrm{Cr}$ (III) oxidation to $\mathrm{Cr}(\mathrm{VI})$ is primarily mediated by biogenic $\mathrm{Mn}(\mathrm{IV})$ oxides [5-7], and the synthetic counterpart $\delta-\mathrm{MnO}_{2}$ has been used to assess the lability of synthetic $\mathrm{Cr}$ (III)-bearing phases [8, 9]. However, no published study to date has used this method to assess the stability of $\mathrm{Cr}$ (III) carrier phases generated by a lab-scale in situ chemical reduction study.

Because the trivalent form of $\mathrm{Cr}$ is less soluble and toxic than its hexavalent form, chemical reduction of $\mathrm{Cr}$ is a potential remediation strategy referred to as in situ chemical reduction (ISCR) when used for remediation purposes. However, to work effectively, it is advantageous that any applied reduction method produces an insoluble $\mathrm{Cr}$ (III)-bearing product that is resistant to oxidation. At earth surface conditions, $\mathrm{Cr}$ (III) typically precipitates as a poorly-crystalline hydroxide $[10,11]$, which is vulnerable to dissolution and subsequent re-oxidation. On the other hand, coprecipitation of $\mathrm{Cr}$ (III) with Fe oxides results in a $\mathrm{Cr}$ (III) carrier phase that is more insoluble and resistant to oxidation. Therefore, any applied ISCR method should attempt to produce a $\mathrm{Cr}$ (III)-substituted Fe(III) oxyhydroxide product.

Green rust (GR) is a Fe (II)-Fe (III) layered double hydroxide (LDH) and has been shown to effectively reduce various contaminants causing their immobilisation, including chromium, yet in many cases the actual reduction mechanisms are still unclear. Green rust is composed of brucite-like $\mathrm{Fe}(\mathrm{OH})_{2}$ sheets in which a portion of the $\mathrm{Fe}^{2+}$ has been replaced by $\mathrm{Fe}^{3+}$, giving the sheets a positive charge. This positive charge is balanced by interlayer anions, where cations such as $\mathrm{Na}^{+}$are also present [12]. There are two types of green rust, distinguished by their interlayer spacings and associated anions. Green rust 1 has a narrow interlayer spacing of $\sim 8 \AA$ occupied by chloride or carbonate, while green rust 2 has a broad interlayer spacing ( $11 \AA$ ) typically occupied by sulfate, which allows exchange of tetrahedral oxyanions and subsequently reduction and sequestration of these substances in the reaction product's interlayer [13-15]. Therefore, it is a promising reagent for exchange and/or reduction of selected groundwater contaminants such as As $[16,17], \mathrm{NO}_{3}{ }^{-}[18,19]$, U (VI) $[15,20]$, Se (VI) [21, 22], Np [23] and Cr(VI) [13, 14, 24-28].
The most commonly-identified product of chromate reduction by green rust is a poorly-crystalline $\mathrm{Cr}(\mathrm{III})-\mathrm{Fe}$ (III) oxyhydroxide [13, 24, 25] or a Cr(III)-Fe (III) oxyhydroxycarbonate when green rust carbonate is used $[26,27]$. However, Cr(III)-bearing goethite has also been observed to form [14] at the green rust particle rims when $\mathrm{Cr}$ concentrations are high and an excess of green rust is added to a batch reaction. Bond and Fendorf [13] and Skovbjerg et al. [14] concluded that these products formed due to exchange of chromate for interlayer sulfate followed by reduction. More recently, our previous study [28] reacted green rust with a series of initial chromium concentrations typical of contaminant plumes and determined that the speciation of chromium in the reaction product is correlated to the initial concentration. Although more goethite was found in the reaction products formed at higher initial concentrations, $\mathrm{Cr}$ (III) hydroxide, presumably located on the oxidized green rust particle surfaces, was the primary $\mathrm{Cr}$ (III) carrier phase produced. A similar side product was also identified by Legrand et al. [27]. The variable $\mathrm{Cr}$ (III) carrier phases identified under varying reaction conditions suggest that several reaction mechanisms are possible: reduction at the particle surface coupled to electron donation from the particle's interior is expected to produce $\mathrm{Cr}$ (III) hydroxide, while $\mathrm{Cr}$ (III)-bearing $\mathrm{Fe}(\mathrm{III})$ oxyhydroxides can form when $\mathrm{Cr}(\mathrm{VI})$ is reduced in the interlayer following exchange of chromate for sulfate.

Like magnetite, green rust is a low-bandwidth semiconductor, and electron transfer from structural Fe(II) in the particles' interior to the surface is possible via a polaron hopping mechanism [29]. A polaron is a quasiparticle consisting of an electron (hole) and the associated distortions in the surrounding lattice [30]. According to the polaron hopping model, which matches empirical observations [31,32] of electron conductivity in metal oxides and other polaronic insulators, electron conduction can only take place via Fe(II)-Fe(III) charge transfer steps, each of which depends on superexchange coupling induced by intermediate cation-centered octahedra [29], as this transition would otherwise be spin-forbidden [33]. Incorporation of divalent and trivalent cations that have no net spin and only a single available oxidation state (e.g. $\mathrm{Al}^{3+}, \mathrm{Mg}^{2+}$ and $\mathrm{Zn}^{2+}$ ) may prevent or slow regeneration of $\mathrm{Fe}(\mathrm{II})$ at the particle surface, as these cations canot accept or donate electrons as part of a transfer chain [34] and may interfere with the superexchange coupling [35] that drives the rapid electron transfer modelled by Wander et al. [29]. In this case, $\mathrm{Cr}(\mathrm{VI})$ may only be able to access $\mathrm{Fe}(\mathrm{II})$ in the green rust crystal interior by exchanging for interlayer sulfate, which would lead to $\mathrm{Cr}$ (III) incorporation into a Fe(III) oxide product, although passivation of the particle may be an issue, as formation of an 
interlayer precipitate may hinder access to interior Fe(II). Since reduction at the surface depends on conduction of interior electrons to the surface, changes in the green rust particle's electrical conductivity can lead to changes in the dominant reaction mechanism. Despite this, few studies have measured the $\mathrm{Cr}$ reactivity of green rusts with cation impurities incorporated into the octahedral layer. Ruby et al. [36] investigated the structure and formation of $\mathrm{Al}$-substituted green rust sulfate, while recent studies ofits reactivity with hexavalent chromium found that it reduced $\mathrm{Cr}(\mathrm{VI})$ more quickly than unsubstituted green rust, suggesting that cation-substituted green rusts may be more effective in situ chemical reduction reagents than the pure form. Green rust sulfates with isomorphic substitutions of $\mathrm{Mg}^{2+}$ [37] and $\mathrm{Zn}^{2+}$ [38] have also been synthesized, but no published study has investigated their reactivity.

Previous investigations of chromate reduction by green rust have returned inconsistent results, possibly due to variations in synthesis techniques and reaction conditions across multiple studies. In the present study, pure sulfate GR and sulfate GR with isomorphic substitution of $\mathrm{Al}, \mathrm{Mg}$, and $\mathrm{Zn}$ were synthesized and reacted with $\mathrm{Cr}(\mathrm{VI})$. The lability of $\mathrm{Cr}(\mathrm{III})$ in the reaction products was then determined by measuring the release of $\mathrm{Cr}(\mathrm{VI})$ after treatment with synthetic $\delta-\mathrm{MnO}_{2}$, the synthetic counterpart of biogenic Mn oxide which has been used to assess $\mathrm{Cr}$ lability in previous studies [7-9]. The structure and $\mathrm{Cr}$ speciation of these products were also determined using transmission electron microscopy (TEM), X-ray absorption spectroscopy (XAS), X-ray diffraction (XRD) and pair distribution function (PDF) analysis.

\section{Methods/experimental}

\section{Green rust and feroxyhyte synthesis and characterization}

All green rusts (green rust sulfate, Al-GR, Mg-GR, Zn-GR) were synthesized using the method from Géhin et al. [39] with metal sulfate salt reagents added to $\mathrm{N}_{2}$-purged Milli-Q water. The total metal concentration in all synthesis batches was $0.1 \mathrm{~mol} \mathrm{~kg}{ }^{-1}$, with divalent to trivalent cation ratios of 3:1. To synthesize the substituted green rusts, the synthesis solutions prior to titration by $\mathrm{NaOH}$ were prepared by replacing $10 \%$ of the $\mathrm{Fe}^{2+}$ or $\mathrm{Fe}^{3+}$ by the desired cation (see Table 1). After synthesis, the green rusts were aged in solution for $48 \mathrm{~h}$. The composition of the solid phase was then calculated by subtracting the values measured using ICP-OES, and aqueous $\mathrm{Fe}^{2+}$ concentrations were measured using the ferrozine method [40] after centrifuging the green rust suspensions and filtering the supernatant using the aforementioned $0.2 \mu \mathrm{m}$ syinge filters. Feroxyhyte $(\delta-\mathrm{FeOOH})$ was synthesized using a method utilizing rapid $\mathrm{Fe}^{2+}{ }_{\text {(aq) }}$
Table 1 Summary of green rust chemical compositions and associated $\mathrm{Fe}^{2+}$ concentrations

\begin{tabular}{|c|c|c|}
\hline Reactant & Expected chemical composition ${ }^{a}$ & $\begin{array}{l}{\left[\mathrm{Fe}^{2+}\right]_{(\mathrm{aq})}} \\
(\mathrm{mmol} \\
\left.\mathrm{L}^{-1}\right)^{\mathrm{b}}\end{array}$ \\
\hline $\mathrm{GR}^{-\mathrm{SO}_{4}}$ & $\mathrm{Fe}_{4}^{\prime \prime} \mathrm{Fe}_{2}^{I I I}(\mathrm{OH})_{12} \mathrm{SO}_{4} \cdot 2 \mathrm{H}_{2} \mathrm{O}$ & 25 \\
\hline Al-GR & $\mathrm{Fe}_{4}^{\prime \prime} \mathrm{Fe}_{1.9}^{\prime \prime \prime} \mathrm{Al} \mathrm{O} .1_{1}(\mathrm{OH})_{12} \mathrm{SO}_{4} \cdot 2 \mathrm{H}_{2} \mathrm{O}$ & 27 \\
\hline$M g-G R$ & $\mathrm{Fe}_{3.8}^{\prime \prime} \mathrm{Mg}_{0.2} \mathrm{Fe}_{2}^{\prime \prime \prime}(\mathrm{OH})_{12} \mathrm{SO}_{4} \cdot 2 \mathrm{H}_{2} \mathrm{O}$ & 23 \\
\hline Zn-GR & $\mathrm{Fe}_{3.8}^{\prime \prime} \mathrm{Zn}_{0.2} \mathrm{Fe}_{2}^{\prime \prime \prime}(\mathrm{OH})_{12} \mathrm{SO}_{4} \cdot 2 \mathrm{H}_{2} \mathrm{O}$ & 23 \\
\hline
\end{tabular}

${ }^{a}$ Based on ratio of cations in solution prior to titration

${ }^{b}$ Expected $\left[\mathrm{Fe}^{2+}\right]_{(\mathrm{aq})}$ is $20-25 \mathrm{mmol} \mathrm{L}^{-1}$

oxidation by $\mathrm{H}_{2} \mathrm{O}_{2}$ [41] and used as a characterization standard for the reacted green rust samples.

\section{$\delta-\mathrm{MnO}_{2}$ synthesis}

Vernalite $\left(\delta-\mathrm{MnO}_{2}\right)$, which resembles natural biogenic Mn (VI) oxides [42], was synthesized using the "redox" method of Villalobos et al. [43]. $\mathrm{MnCl}_{2}$ was added slowly to a $\mathrm{KMnO}_{4}$ solution while maintaining a $\mathrm{pH}$ of 7 using $\mathrm{NaOH}$. The product was first rinsed several times with $1 \mathrm{M} \mathrm{NaCl}$ to remove the remaining $\mathrm{Mn}^{2+}$, then with Milli-Q water before further purification using dialysis. Vernalite was kept in suspension by sonication and adjusted to $\mathrm{pH} 7.5$ before use in re-oxidation batch reactors.

\section{Batch reactions}

Three replicate batch reactors were set-up for each synthesized green rust type: one for solid phase characterization and two to measure $\mathrm{Cr}(\mathrm{VI})$ reduction and $\mathrm{Cr}(\mathrm{III})$ re-oxidation by $\delta-\mathrm{MnO}_{2}$. All batch reactions were performed in an anaerobic chamber with an Ar atmosphere. In each reactor, an aliquot of green rust suspension with about $0.2 \mathrm{mmol}$ of $\mathrm{Fe}$ (II) was added to a $100 \mathrm{~mL}$ $0.67 \mathrm{mmol} \mathrm{kg} \mathrm{K}_{2} \mathrm{CrO}_{4}$ solution in an acid-washed borosilicate beaker $([\mathrm{Fe}(\mathrm{II})] /[\mathrm{Cr}(\mathrm{VI})] \leq 3$, slight excess of $\mathrm{Cr}(\mathrm{VI})$ to ensure complete oxidation and prevent the $\mathrm{Fe}^{2+}$-catalyzed transformation of reaction products), with the $\mathrm{pH}$ of all solutions adjusted to 7 . The batch reactions were not shielded from the light as this would have prevented sample removal, and the reaction temperature and $\mathrm{pH}$ were not controlled to allow direct comparison to similar studies that followed the same procedure [14, 28]. The first reaction was terminated after 7 days by filtration $(0.2 \mu \mathrm{m}$, Whatman nylon membrane filter), and solid samples were removed for further characterization. Aging for 7 days allowed incipient transformation of the initial metastable intermediate $[14,28]$. In the second and third reactors, suspension aliquots were periodically removed and filtered during the first hour of the 
reaction to monitor the removal of $\mathrm{Cr}(\mathrm{VI})$ by $\mathrm{GR}$ reduction; after 7 days, colloidal, synthetic $\delta-\mathrm{MnO}_{2}$ was added to the remaining suspension. Samples removed prior to and 1 and 2 weeks after $\delta-\mathrm{MnO}_{2}$ addition were treated with $10 \mathrm{mM} \mathrm{Na}_{2} \mathrm{HPO}_{4}$ for $24 \mathrm{~h}$ to desorb chromate from mineral surfaces, followed by filtration. $[\mathrm{Cr}(\mathrm{VI})]$ in all samples was measured using the 1,5-diphenylcarbazide method (US Environmental Protection Agency (EPA) method 7196A) with a Perkin-Elmer Lambda 2S UV-Vis Spectrophotometer calibrated using a four-point calibration curve. In addition, measurement of $\left[\mathrm{Fe}^{2+}{ }_{(\mathrm{aq})}\right]$ by the ferrozine method was attempted, but the results are not shown here because $\left[\mathrm{Fe}^{2+}{ }_{(\mathrm{aq})}\right]$ decreased to below the limit of detection within ten seconds.

\section{X-ray diffraction (XRD) and pair distribution function (PDF) analyses}

Benchtop XRD measurements were performed using a Bruker D8 Diffractometer. Unreacted green rust samples were removed from suspension by filtration, treated with glycerol to prevent oxidation, and transferred as a paste to a standard $\mathrm{Si}$ powder specimen holder. X-rays were emitted from a $\mathrm{Cu}-\mathrm{K} \alpha$ source $(\lambda=1.5418 \AA)$, and data were collected at $2 \theta$ values between 2 and $82^{\circ}$ with a step size of $0.02^{\circ}$ and an average counting time of $1 \mathrm{~s}$ per step. Background diffraction patterns were collected by measuring an empty sample holder, and the XRD-BS software was used to remove the background from the sample data.

Synchrotron X-ray scattering measurements of reacted samples were performed at beamline 11-ID-B at the Advanced Photon Source (APS) at Argonne National Laboratory, using an X-ray energy of $58.66 \mathrm{keV}$ $(\lambda=0.2113 \AA)$. Samples were ground and transferred into glass capillaries sealed with paraffin, then measured at a distance of $\sim 18 \mathrm{~cm}$ (PDF) and $100 \mathrm{~cm}$ (XRD) using a $40 \mathrm{~cm} \times 40 \mathrm{~cm}$ amorphous Si 2D detector. An empty glass capillary and a $\mathrm{CeO}_{2}$ standard were also measured for background subtraction and calibration of the Laue patterns, respectively. The collected patterns were converted to $1 \mathrm{D}$ data using the Fit2D software after calibrating the geometry of the setup using the $\mathrm{CeO}_{2}$ standard. For high resolution XRD, the $\mathrm{I}(\mathrm{Q})$ data collected at $100 \mathrm{~cm}$ was treated with the software GSAS-II [44] to perform background subtraction, and to convert the incident beam energy to $\mathrm{Cu}-\mathrm{K} \alpha(\lambda=1.5406 \AA)$ for comparison with lab based XRD. Full width half maximum (FWHM) values for the green rust $\{213\}$ reflection were determined using the peak fitting extension in OriginPro 2018. PDF patterns were extracted from the data collected at $18 \mathrm{~cm}$ using the software PDFGetX3 [45], including background subtraction and corrections for incoherent scattering and non-linear detector efficiency as well as normalization to the sample's average atomic scattering cross-section [46]. The composition of the sample was set at $\mathrm{Fe}_{0.5} \mathrm{Cr}_{0.12} \mathrm{O}_{0.38}$ due to the stoichiometry of the reaction. Fourier transformation of the reduced structure function $\mathrm{Q}\left[\mathrm{S}(\mathrm{Q})^{-1}\right]$ was performed using a maximum Q-value of $20 \AA^{-1}$ to yield G (r), the reduced pair distribution function.

\section{X-ray absorption spectroscopic (XAS) analyses and data processing}

Bulk XAS spectra of all reacted samples were collected at the SUL-X beamline at the ANKA synchrotron facility in Eggenstein-Leopoldshafen, Germany, which operates at $2.5 \mathrm{GeV}$. The incident beam was scanned through the $\mathrm{Cr}$ and Fe K-edges (set at $5989 \mathrm{eV}$ and $7112 \mathrm{eV}$ for metallic $\mathrm{Cr}$ and $\mathrm{Fe}$, respectively), using a $\mathrm{Si}$ (111) crystal pair monochromator with a fixed-beam exit. Higherorder harmonics were removed from the incident beam using a grazing incidence mirror. Three replicates of each spectrum were measured in both transmission and fluorescence mode in a range of -200 to $1000 \mathrm{eV}$ relative to the absorption edge. Transmission spectra were obtained using three Oxford Instruments IC-type ionization chambers with Kapton windows, and fluorescence measurements were obtained using a Gresham 7-element Si (Li) detector. All spectra were calibrated with a $\mathrm{Cr}$ or $\mathrm{Fe}$ metal foil placed between ionization chambers 2 and 3 .

$\mathrm{Fe}$ and Cr XAS data were processed and analyzed using the Demeter software package [47]. All analyses were performed on spectra obtained in transmission mode. After calibrating the spectral energies using reference metal foil spectra, a merged spectrum was produced by averaging the three replicate spectra in $\mu(E)$-space. The merged spectra were then normalized using a first-order pre-edge function and a third-order post-edge spline function to model the background absorption.

For $\mathrm{Cr}$ X-ray absorption near-edge spectroscopy (XANES) linear combination fitting, the derivative of each $\mu(E)$ spectrum was fitted to two reference standards (Cr(III)-bearing ferrihydrite and $\mathrm{Cr}(\mathrm{III})$ hydroxide [48, $49])$ in the XANES region $(-20$ to $+30 \mathrm{eV})$. No further constraints were placed on the fit. Fe K-edge extended $\mathrm{X}$-ray absorption fine-structure spectroscopy (EXAFS) fitting was also performed, and due to the similarity of the spectra to feroxyhyte, the procedure for fitting of a feroxyhyte spectrum outlined in Manceau and Drits [50] was followed. Where possible, the $k^{3}$-weighted EXAFS spectra were Fourier transformed over a $k$-range of $4-14 \AA^{-1}$; other ranges were used when the data at high $k$-values was too noisy or a Co K-edge was present in this region (oxGR). Shell-fitting was performed using the Artemis software. Theoretical Fe phase and amplitude functions were calculated from the crystal structure of hematite 
[51] with no further modifications. During fitting, $S_{0}^{2}$ was fixed at 0.9 and all $\sigma^{2}$ values were fixed at 0.015 , as the fitted value of this parameter tended to converge to 0.015 when the fits were performed. All fits were performed using three single-scattering paths: $\mathrm{Fe}-\mathrm{O}(1.98$ $\AA)$, edge-sharing $\mathrm{Fe}-\mathrm{Fe}(3.01 \AA)$, and corner-sharing $\mathrm{Fe}-$ Fe $(3.4 \AA)$. Other single- and multiple-scattering pathways were tested but ultimately excluded because they failed to improve the fit or produced unphysical parameter solutions. A more detailed outline of the Fe K-edge EXAFS fitting procedure is included in Additional file 1: Appendix 2.

\section{Electron microscopy}

Scanning electron microscopy (SEM) images of unreacted green rusts were recorded on an FEI Quanta 3D FEG microscope. Samples were prepared inside an anaerobic chamber by filtering an aliquot of a green rust suspension through a $0.2 \mu \mathrm{m}$ nylon filter, and the paste was transferred to an SEM sample holder. The samples were then immediately transferred to the microscope's vacuum chamber to prevent oxidation. Images were obtained in high vacuum mode at an accelerating voltage of $20 \mathrm{kV}$ using an Everhart-Thornly secondary electron detector.

Higher resolution images of green rust samples reacted with $\mathrm{Cr}(\mathrm{VI})$ were recorded using a TEM on samples prepared by transferring several drops of a sonicated suspension in ethanol to a $3 \mathrm{~mm} \mathrm{Cu}$-TEM grid coated with a holey amorphous carbon film. The TEM grids were then transferred to a FEI Tecnai TEM operated at $200 \mathrm{kV}$ and equipped with a Gatan Tridiem imaging filter (GIF), a
Fishione high-angle annular dark field detector, an energy dispersive X-ray (EDX) analyzer to measure chemical composition and a Gatan Orius SC200D $4 \mathrm{~K}$ pixel cooled CCD camera. Selected-area electron diffraction (SAED) patterns were collected using plates with an aperture of ca. 200-300 nm and developed in a Ditabis Imaging Plate Scanner. The d-spaces and FWHM values were calculated from manual measurements obtained using the ImageJ software. TEM images were processed and converted using Gatan DigitalMicrograph, while the raw EDX data was processed using EDX Quant.

\section{Results and discussion}

Characterization, reduction of $\mathrm{Cr}(\mathrm{VI})$ and reaction product stability

Based on the measurements shown in Table 1, all green rust suspensions have similar aqueous $\mathrm{Fe}^{2+}$ concentrations which are similar to the expected concentrations based on the 2:1 ratio of $\mathrm{Fe}(\mathrm{II})$ to $\mathrm{Fe}(\mathrm{III})$ in green rust sulfate. Mg- and Zn-GR are associated with slightly lower $\mathrm{Fe}^{2+}$ concentrations, however, most likely because $10 \%$ of the Fe(II) in these suspensions (compared to pure GR) is replaced by $\mathrm{Mg}$ or $\mathrm{Zn}$. As aqueous $\mathrm{Fe}^{2+}$ can also reduce $\mathrm{Cr}(\mathrm{VI})[11,48,52]$, the inconsistent $\mathrm{Fe}^{2+}$ concentrations shown in Table 1 may result in differing Cr-bearing phases in the products of these reactions, as discussed later.

Figure 1 shows the benchtop XRD patterns of the synthetic green rusts prior to reaction with hexavalent chromium. All patterns had the same green rust 2 peaks predicted by the crystal structure from Simon et al. [53],

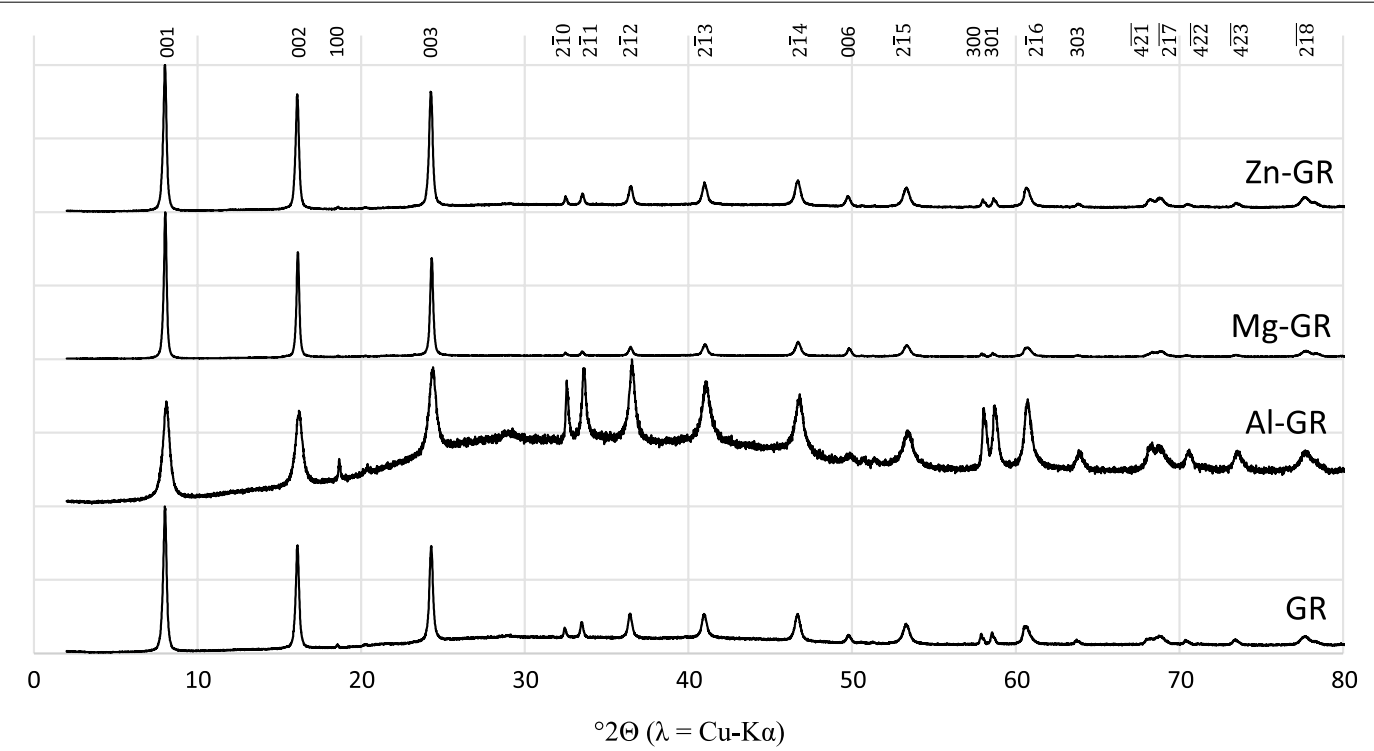

Fig. 1 XRD patterns obtained after aging synthetic, unreacted green rusts for $24 \mathrm{~h}$. Miller indices apply to all diffraction patterns where the selected reflection is present and are assigned based on the green rust sulfate structure from Simon et al. [53] 
but there were differences in peak amplitude and shape. $\mathrm{Al}$ substitution for $\mathrm{Fe}(\mathrm{III})$ resulted in an $87 \%$ increase in the FWHM of the $\{213\}$ peak at $41^{\circ} 2 \theta$ relative to GR, suggesting that $\mathrm{Al}$ substitution either increases the structural disorder or decreases the crystallite size in the green rust as observed in previous studies [36]. Representative SEM images (Fig. 2) show that all green rusts have a characteristic hexagonal morphology, but the substituted green rust particle morphologies are more irregular than pure green rust. In addition, it is clear that the substituted green rusts have broader particle size distributions, possibly due to non-uniform incorporation of $\mathrm{Al}, \mathrm{Mg}$ and Zn.

The removal of chromate by the various green rust sulfates is shown in Fig. 3a. In all cases, chromate concentrations are reduced to below the detection limit (0.04 mg kg-1, below the WHO-recommended limit of $0.05 \mathrm{mg} \mathrm{kg}^{-1}$ ) after $10 \mathrm{~min}$ of reaction time; however, $\mathrm{Cr}(\mathrm{VI})$ is removed from solution much more rapidly by pure green rust and $\mathrm{Al}-\mathrm{GR}$, while substitution by zinc and magnesium led to slower removal of $\mathrm{Cr}(\mathrm{VI})$ from solution. This may be due to differences in particle size (Fig. 2) and/or $\left[\mathrm{Fe}^{2+}{ }_{(\text {aq) }}\right]$ concentration; several Mg-GR and Zn-GR particles with diameters near $700 \mathrm{~nm}$ are visible, possibly indicating that $\mathrm{Mg}-\mathrm{GR}$ and $\mathrm{Zn}$-GR have lower reactive surface areas, and $\mathrm{Fe}^{2+}$ reacts more rapidly with chromate than structural $\mathrm{Fe}(\mathrm{II})$ [52]. Our previous study [28] measured $\mathrm{Cr}(\mathrm{VI})$ reduction at different chromium concentrations, finding that green rust consistently reduces all chromium in solution, but the reaction rate decreases with the chromium concentration.

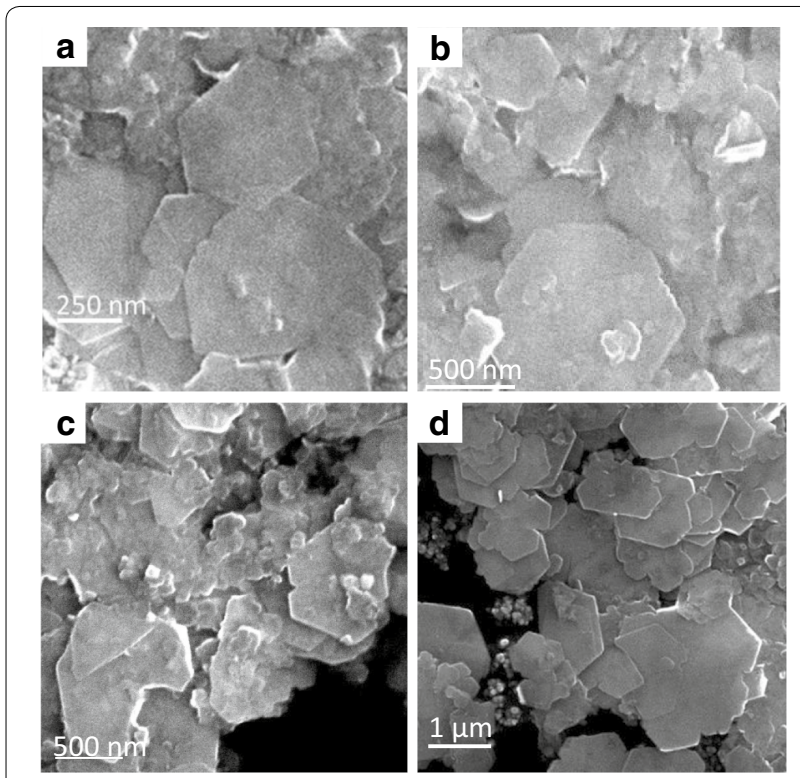

Fig. 2 SEM micrographs of GR (a), Al-GR (b), Mg-GR (c) and Zn-GR (d)

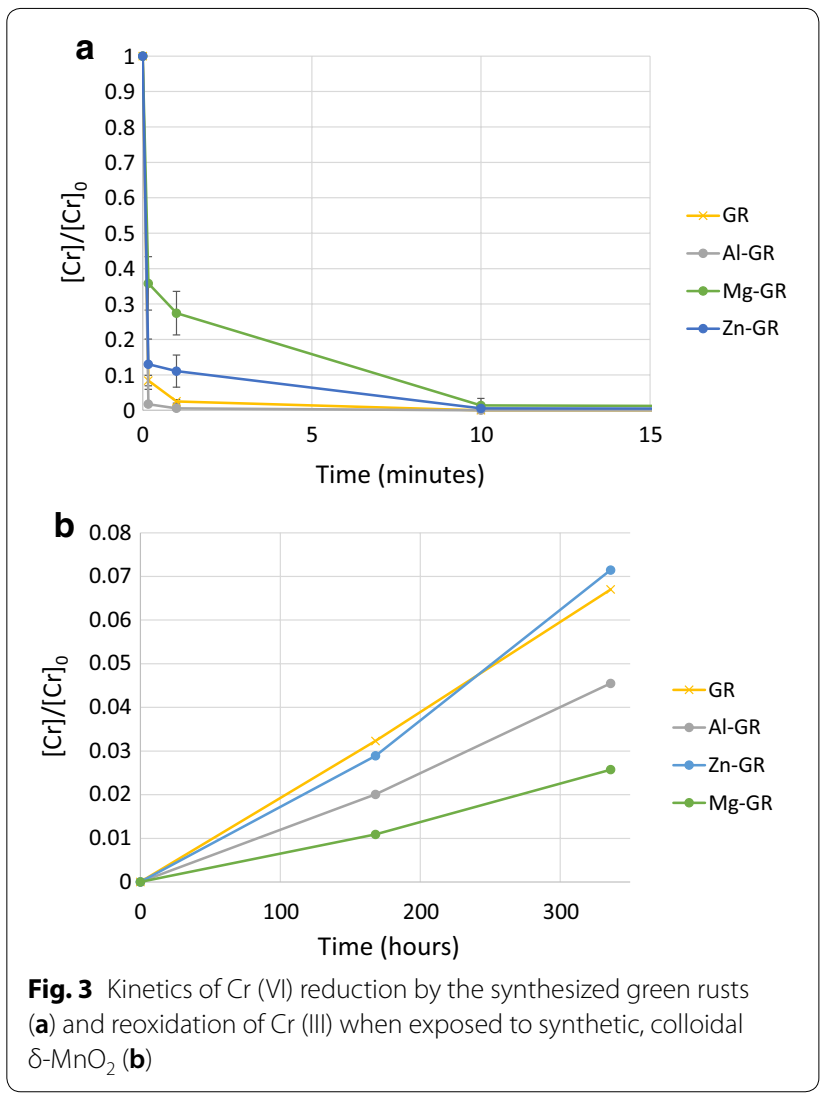

It is unknown whether the differences in reaction rate between the green rusts tested in the present study are consistent at other chromium concentrations. Figure $3 \mathrm{~b}$ shows the release of chromate, i.e. re-oxidation of $\mathrm{Cr}(\mathrm{III})$ to $\mathrm{Cr}(\mathrm{VI})$ by colloidal $\delta-\mathrm{MnO}_{2}$. Approximately $7 \%$ of the reduced chromium in the pure green rust and $\mathrm{Zn}$-bearing green rust reaction products were re-oxidized $\left([\mathrm{Cr}]=2.4 \mathrm{mg} \mathrm{kg}^{-1}\right)$, compared to $2.5 \%([\mathrm{Cr}]=$ $\left.0.9 \mathrm{mg} \mathrm{kg}^{-1}\right)$ and $4.5 \%\left([\mathrm{Cr}]=1.6 \mathrm{mg} \mathrm{kg}^{-1}\right)$ of the $\mathrm{Cr}$ in the product of $\mathrm{Mg}$ - and Al-bearing green rust, respectively. These differences most likely result from differences in the particle structure and $\mathrm{Cr}$ speciation of the reaction byproducts, which are discussed below.

\section{Long-range order structure and particle morphology of reaction products}

Synchrotron XRD patterns of solids formed after reacting the GRs with $\mathrm{Cr}$ for 7 days are shown in Fig. 4. For simplicity, all reaction products in this publication will be identified as oxGR (oxidized green rust sulfate) or oxnGR $(n=\mathrm{Al}, \mathrm{Mg}$ or $\mathrm{Zn})$. Two broad reflections at $2.55 \AA$ $\left(2 \theta=35.2^{\circ}\right)$ and $1.46 \AA\left(2 \theta=63.7^{\circ}\right)$ are the most notable features present in each pattern. These spacings were also observed in the oxidized green rust diffraction patterns from Skovbjerg et al. [14] and are characteristic of 


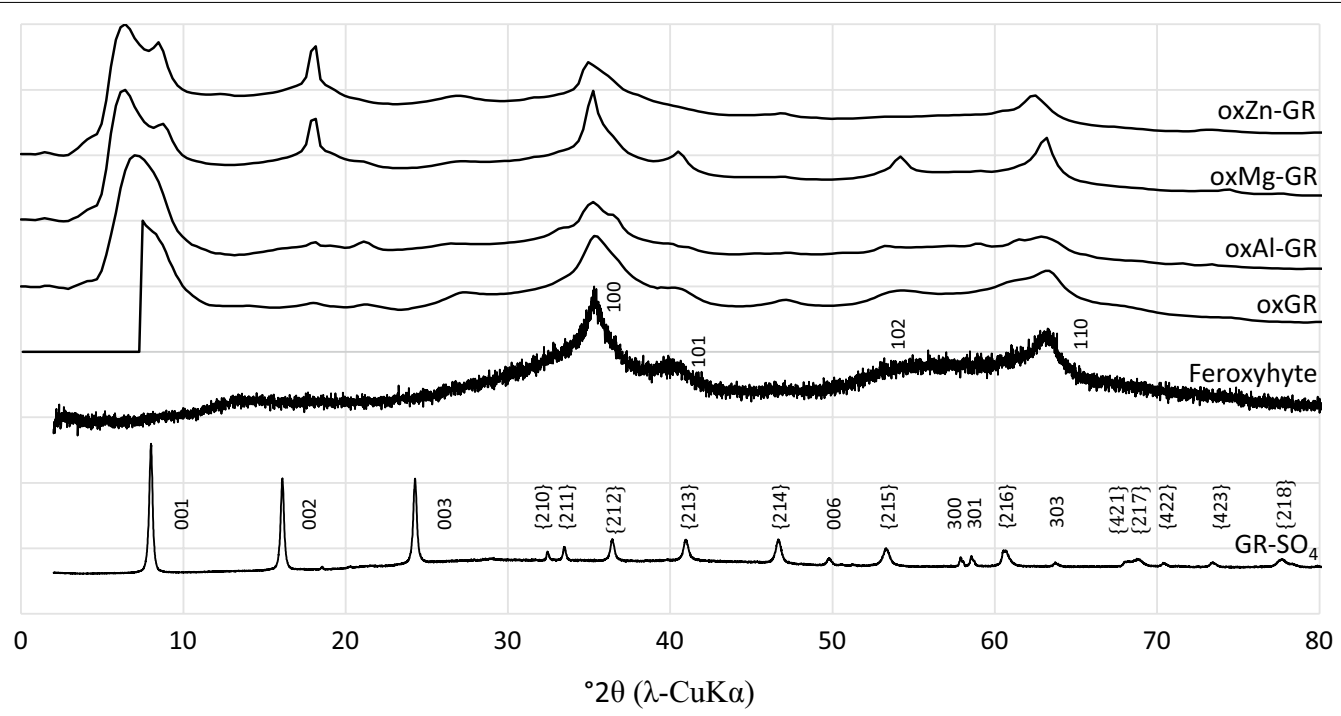

Fig. 4 X-ray diffraction patterns of reacted samples and reference standards synthesized for comparison. X-axis recalculated to represent patterns in terms of $2 \theta$ (CuKa). Miller indices assigned based on unit cell structures of green rust sulfate (Simon et al. [53]) and feroxyhyte (Patrat et al. [54])

many Fe oxides with hexagonal symmetry such as ferrihydrite and feroxyhyte $[54,55]$ and most likely indicate a residual hexagonal symmetry remaining after oxidation and restructuring of the green rust. However, the broadness of these peaks suggests structural disorder in the [001] crystallographic direction. In the case of oxMg-GR, partial transformation to feroxyhyte is also evident, as the broad $2.55 \AA$ and $1.46 \AA$ reflections are sharper and several minor feroxyhyte reflections at $\sim 40.5^{\circ}(101)$ and $54.2^{\circ} 2 \theta$ (102) are also visible in this XRD pattern. Every sample is also partially composed of a residual layered ferric green rust structure, as shown by a broad, diffuse reflection below $8^{\circ} 2 \theta$ [14], which is much more prominent in the wet sample diffraction pattern (Additional file 1: Fig. S1) obtained using a Bragg-Bretano instrument. Therefore, the broadening of this peak is most likely due to drying of the sample prior to measurement, which can dehydrate the interlayer to a variable degree and cause stacking distance variability in the [001] direction. A reflection at about $10.4 \AA\left(2 \theta=8.5^{\circ}\right)$ is also visible in the oxMg-GR and oxZn-GR patterns; this reflection is similar to the (001) reflection in green rust sulfate and suggests that the original, hydrated structure has been preserved to some extent. These reflections are also visible in Additional file 1: Figure S1, but the data is much noisier and many minor peaks are not visible. In addition, a minor reflection at $4.9 \AA\left(2 \theta=18.1^{\circ}\right)$ is present in the oxMg-GR and oxZn-GR patterns, but the authors were unable to identify the source of this peak. This spacing does not correspond to any known iron oxide structure.
Figure 5 shows TEM images of the various green rust samples after reaction with aqueous chromate. In all samples, the pseudo-hexagonal morphology of the reactant particles remains preserved after oxidation and the particle diameters are similar to those measured in Fig. 2, but the particle edges are more irregular, particularly in the case of oxAl-GR. This sample also has many irregular particular aggregates, but several pseudo-hexagonal particles are visible, particularly the particle from which the SAED pattern was obtained. Higher-contrast domains at the rims of some oxMg- and oxZn-GR hexagonal particles are visible, which are also associated with lower density in the interior domains of the same particle (more easily visible in the STEM (scanning transmission electron microscopy) images, Fig. 5e-f). Although particles with these rim-like domains are present in both oxMgGR and oxZn-GR, they are more prevalent in oxMg-GR. Particles with similar morphologies were identified by Skovbjerg et al. [14], but the rim domains in the present study are more poorly-defined than the domains that formed at chromium levels high enough to oxidize $60 \%$ of the Fe(II) bound in green rust. This study concluded that these features formed due to $\mathrm{Cr}$ reduction by green rust from the rim inwards. Particles with other morphologies (i.e. rods and amorphous aggregates) are also visible.

In the SAED patterns collected from selected hexagonal particles, two hexagonal sets of reflections corresponding to d-spacings of $\sim 2.5$ and $\sim 1.47 \AA$ are also visible in all samples (see Fig. 5 insets) with variable sharpness. These patterns confirm the hexagonal symmetry of the product when observed from the [001] direction and 

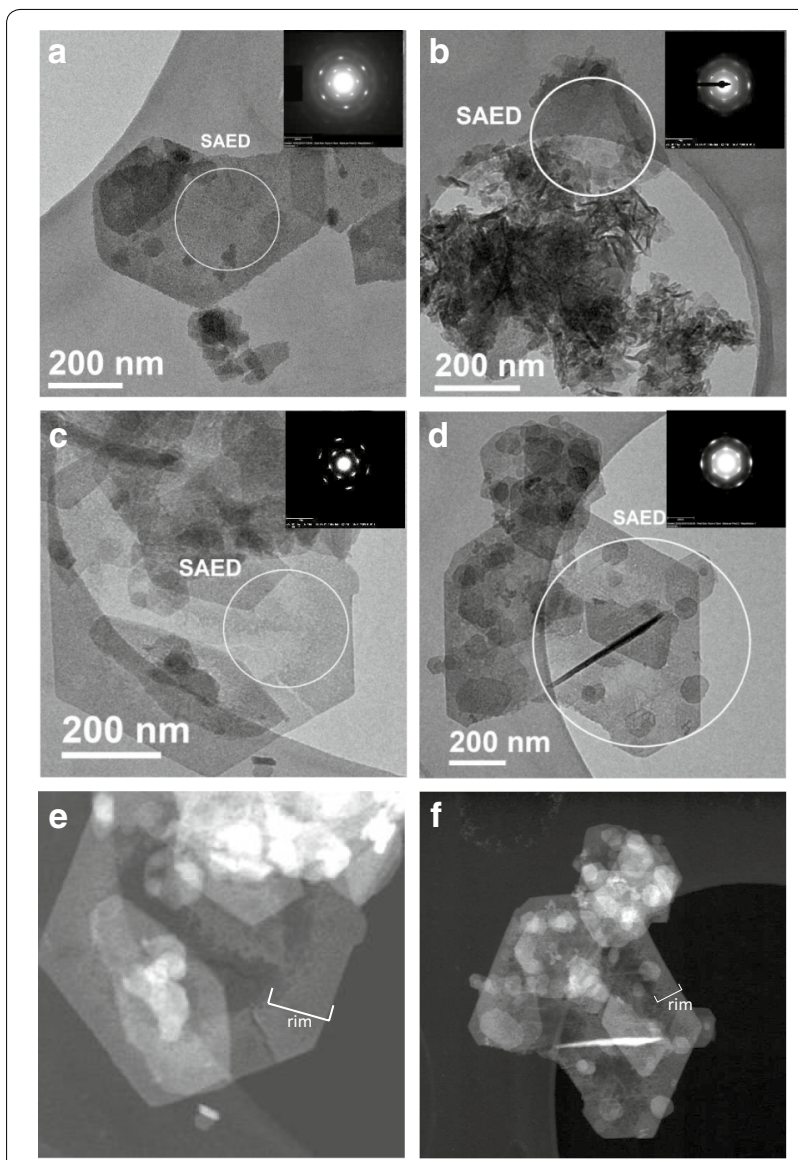

Fig. 5 TEM images of oxGR (a), oxAl-GR (b), oxMg-GR (c) and oxZn-GR (d). STEM images of oxMg-GR (e) and oxZn-GR (f) are also shown. Areas where SAED was performed are indicated, and the SAED patterns are displayed in the insets. FWHM of diffraction spots (mm, at $2.53 \AA / 1.46 \AA$ ): a $0.65 / 1.26, \mathbf{b} 0.71 / 1.51, \mathbf{c} 0.55 / 0.67$, d $0.72 / 1.07$

indicate that there is some coherence between adjacent sheets along this axis. The oxidation product for which the smallest proportion of $\mathrm{Cr}$ was oxidized by $\delta-\mathrm{MnO}_{2}$, oxMg-GR, had a SAED pattern with the lowest calculated peak FWHM values $(\mathrm{mm}$, inner ring/outer ring $=$ $0.55 / 0.67$ ) when measuring in the direction of the center of the pattern, suggesting increased coherency between hydroxide sheets. The corresponding peaks (at $34^{\circ}$ and $63.2^{\circ} 2 \theta$ ) are also sharpest in the oxMg-GR diffraction pattern (Fig. 4b).

Elemental concentration ratios measured by EDX and averaged over all measured hexagonal particles in each sample are shown in Table 2. Spectra taken from nonhexagonal particles were excluded from these calculations. These elemental ratios can determine whether certain elements are enriched or depleted in the various oxGR's that formed during the reactions and also provide insights into the mechanisms that drive enrichment
Table 2 Elemental ratios determined by EDX. Values are averages calculated from measurements of all selected areas

\begin{tabular}{lll}
\hline Sample & {$[\mathrm{Cr}] /([\mathrm{Cr}+\mathrm{Fe}])^{\mathbf{a}}$} & {$[\mathrm{Fe}] /[\mathrm{S}]$} \\
\hline OxGR & $0.19(0.02)(\mathrm{n}=2)$ & $4.21(1.68)(\mathrm{n}=2)$ \\
OxAl-GR & $0.142(0.012)(\mathrm{n}=2)$ & $13.90(2.20)(\mathrm{n}=2)$ \\
oxMg-GR & $0.158(0.052)(\mathrm{n}=7)$ & $31.19(14.45)(\mathrm{n}=7)$ \\
oxZn-GR & $0.179(0.074)(\mathrm{n}=8)$ & $13.72(6.94)(\mathrm{n}=8)$ \\
\hline
\end{tabular}

Elemental ratios and uncertainties calculated from all EDX measurements taken from hexagonal particles

a Expected ratio (reaction stoichiometry) is ca. 0.18

or depletion. $\mathrm{Cr} / \mathrm{Fe}+\mathrm{Cr}$ ratios are similar to the ratio $(\sim 0.18)$ predicted by the reaction's stoichiometry (Eq. 1). The value of this ratio is not expected to vary for different topotactic reaction mechanisms, as three structural $\mathrm{Fe}$ (II) atoms are necessary to reduce one $\mathrm{Cr}(\mathrm{VI})$ atom in all cases. The $\mathrm{Fe} / \mathrm{S}$ ratios, which can serve as proxies for exchange of interlayer sulfate, vary widely between samples, although many of these measurements have a large standard deviation. OxGR has a measured $\mathrm{Fe} / \mathrm{S}$ ratio of 4.2, lower than the unreacted green rust ratio of 6.0 (Eq. 1) [12, 39], although the sample size of this measurement is not large enough to determine whether this difference is statistically significant.

$$
\begin{gathered}
0.75 \mathrm{Fe}_{4}^{\mathrm{II}} \mathrm{Fe}_{2}^{\mathrm{II}}(\mathrm{OH})_{12} \mathrm{SO}_{4} \cdot 8 \mathrm{H}_{2} \mathrm{O}+\mathrm{CrO}_{4}^{2-}+0.5 \mathrm{H}^{+} \\
\quad \rightarrow 5.5 \mathrm{Fe}_{0.818} \mathrm{Cr}_{0.182} \mathrm{OOH}+0.75 \mathrm{SO}_{4}^{2-}+8 \mathrm{H}_{2} \mathrm{O}
\end{gathered}
$$

On the other hand, oxMg-GR has a significantly higher $\mathrm{Fe} / \mathrm{S}$ ratio than oxZn-GR and the ratio in unreacted green rust sulfate $(\sim 6.0)$, and it is likely that sulfur has been depleted in this sample, possibly by chromate exchange for sulfate and its subsequent reduction in the interlayer.

\section{PDF and XAS characterization of short-range order structure of reaction products}

The reduced pair distribution functions $G(r)$ calculated for all reaction products produced in this study (Fig. 6) are nearly identical to those observed by Yin et al. [56], who characterized the oxidation products of 3:1 (i.e. $[\mathrm{Fe}(\mathrm{III})] /[\mathrm{Fe}(\mathrm{II})]=3)$ oxidized green rust chloride single sheets separated by dodecanoate intercalation (singlesheet iron oxide, SSI) and green rust sulfate oxidized by an excess of $\mathrm{Cr}(\mathrm{VI})$, respectively. These studies hypothesized that oxidation of the brucite-like layer caused dislocation of part of the Fe (III) into the interlayer, which manifests in the PDF as a splitting of the single green rust peak at $\sim 3.20 \AA[\mathrm{Fe}(\mathrm{II})-\mathrm{Fe}(\mathrm{II})$ and $\mathrm{Fe}(\mathrm{II})-\mathrm{Fe}(\mathrm{III})$ edge sharing] into two peaks at approximately $3.04 \AA$ [Fe(III)$\mathrm{Fe}(\mathrm{III})$ edge-sharing] and $3.41 \AA$ [Fe(III)-Fe(III) corner 


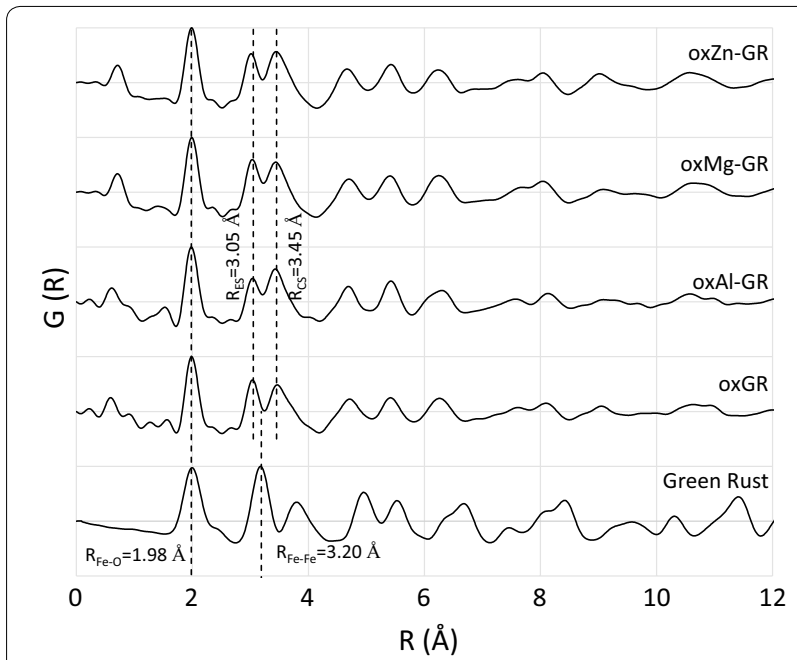

Fig. 6 Calculated pair distribution functions $[G(r)]$ for each measured reaction product, normalized to the intensity of the correlation at $1.98 \AA$. A Cr (III) hydroxide PDF pattern is not available, but has known correlations at 1.98 and $3.0 \AA$ (Tang et al. [57]). Fe-O and Fe-Fe distances referenced in the text are labelled. $R_{E S}$ and $R_{C S}$ correspond to edge-sharing and corner-sharing Fe-Fe distances, respectively sharing], both of which can be seen in the reaction products in Fig. 6, although the peak positions differ slightly (3.05 and $3.45 \AA$ ). . The XRD (Fig. 4) and SAED (Fig. 5) patterns indicate that there is some coherence between the stacked, oxidized layers, but the associated intersheet correlations most likely have amplitudes too low to be visible in the PDF patterns, as random Fe dislocations may remove atomic correlations while leaving the stacking in the [001] direction coherent enough to generate identifiable XRD and SAED reflections.

However, there are significant differences in peak intensity from the Yin et al. [56] PDFs at low R-values, particularly between 3.0 and $3.5 \AA$. The amplitudes of the peaks at $3.05 \AA$ and $3.45 \AA$ are very similar in the present study's PDF patterns while the intensity at $3.41 \AA$ in Yin et al. [56] is greater. Oxidation of 2:1 green rust sulfate (i.e. $[\mathrm{Fe}(\mathrm{II})] /[\mathrm{Fe}(\mathrm{III})]=2$ ) produces a lower layer charge than oxidation of $3: 1$ green rust chloride, and therefore requires a smaller degree of internal rearrangement and deprotonation/hydroxylation to balance this layer charge. In addition, Tang et al. [57] found that PDF patterns of $\mathrm{Cr}$ (III) hydroxide have prominent pair correlations at $1.98 \AA$ and $\sim 3.0 \AA$, which may also contribute to the amplitudes of the peaks at 1.98 and $3.03 \AA$ in Fig. 6, but do not have high enough amplitudes at higher $\mathrm{R}$ to contribute to the pattern in this region due to the small $(>10$ Å) domain sizes.

Figure 7 shows the Fe EXAFS shell-by-shell fits of all reacted green rust products and a feroxyhyte reference standard for comparison, and the associated fit results

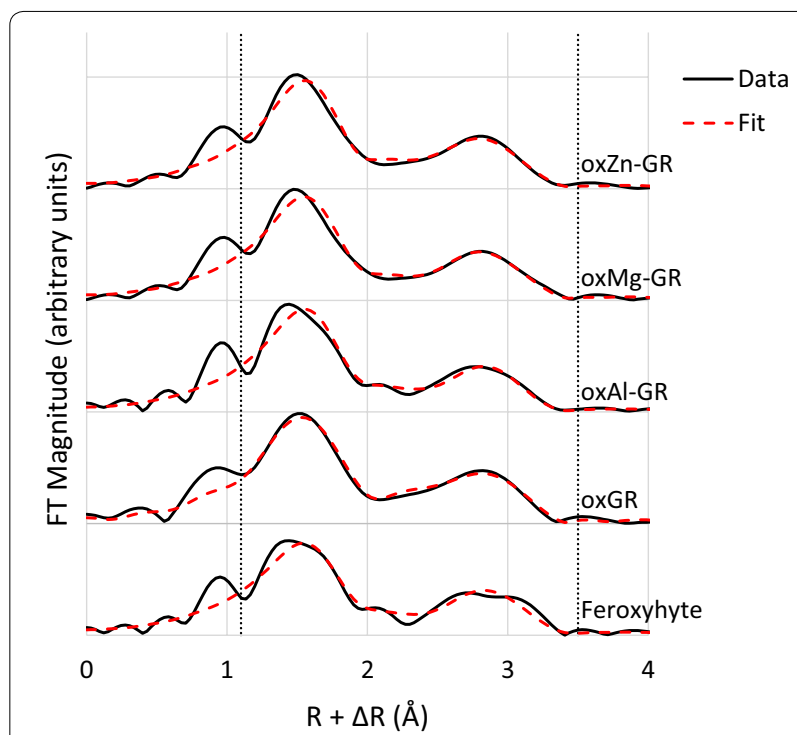

Fig. 7 Fourier transformed Fe K-edge EXAFS spectra and fits after 7 days reaction time, as well as a feroxyhyte spectrum for comparison . Fit statistics and sample-specific fitting parameters outlined in Table 3. Fits performed over an R-range of 1.1-3.5

are listed in Table 3. The short-range $(<4 \AA$ ) bonding environment of $\mathrm{Fe}$ in these samples is characterized by a mix of edge- and corner-sharing $\mathrm{MeO}_{6}$ octahedral linkages at distances of $\sim 3.04$ and $3.4 \AA$, which matches the structure predicted by PDF. The second- and third-shell coordination numbers have ratios similar to the apparent intensity ratios of the corresponding PDF peaks (Fig. 6), and the sums of these coordination numbers are all close to six. Because each Fe octahredron is also surrounded by six $\mathrm{Fe}$ in unreacted green rust sulfate, this supports the formation mechanism suggested by the PDF, as Fe dislocated into the interlayer is still bound to Fe remaining in the octahedral layer. The Fe EXAFS spectra also show that the Fe-bearing phases in all samples resemble feroxyhyte, particularly oxMg-GR, but there are significant differences. All samples have more edge-sharing Fe than feroxyhyte, particularly oxGR and oxZn-GR as well as oxMg-GR, even though feroxyhyte is identifiable in the latter sample by XRD. This may be due to features such as the brucite-like sheet inherited after the transformation, as this sheet, which is dominated by edge-sharing linkages, has fewer vacancies than a similar feroxyhyte structure $[54,58]$ if the transformation is topotactic. In addition, the two shells at 3.04 and $3.41 \AA$ are distinct in the feroxyhyte spectrum but merged into a single shell in the sample spectra, suggesting that these samples have a significantly higher degree of structural disorder than synthetic feroxyhyte.

XANES linear combination fits were also performed on all Cr K-edge XAS spectra, using synthetic $\mathrm{Cr}$ (III) 


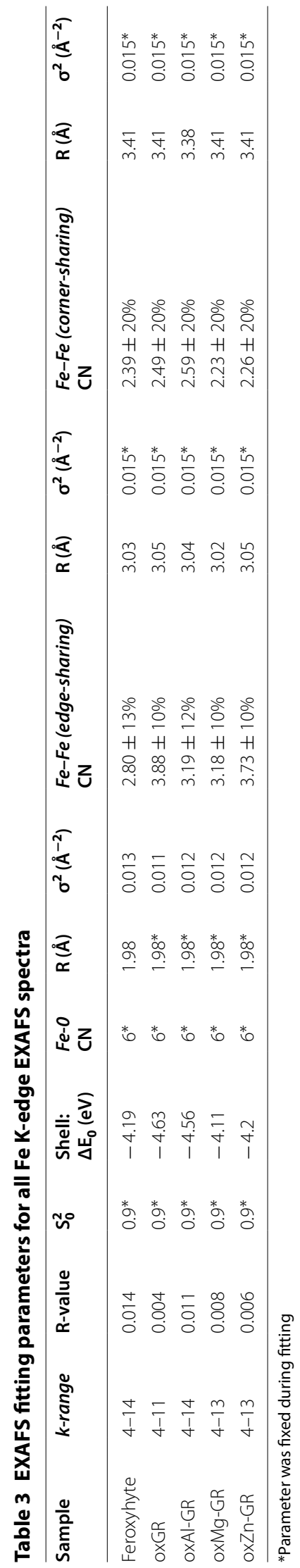




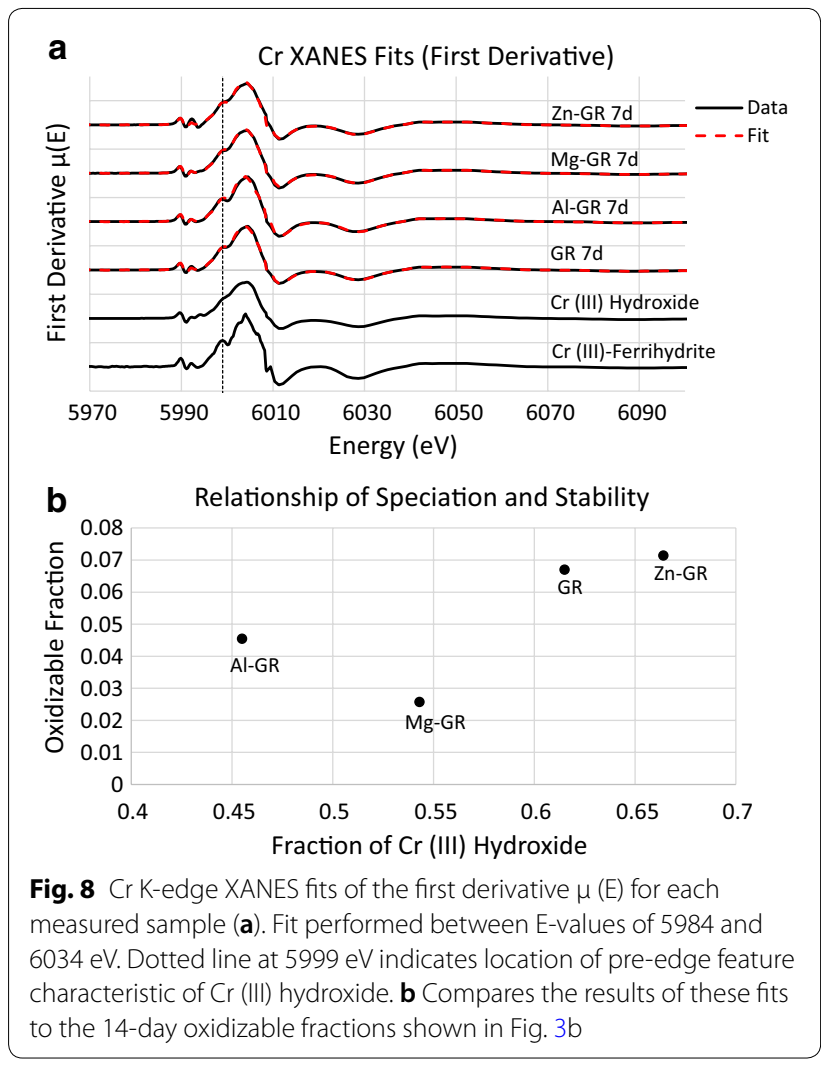

hydroxide and $\mathrm{Cr}$ (III)-bearing ferrihydrite as reference standards (Fig. 8a, fit results and statistics shown in Table 4). Cr(III)-bearing ferrihydrite, which is used here in the absence of other $\mathrm{Cr}$ (III)-bearing Fe oxyhydroxide reference standards, can be identified in the XANES spectra by characteristic pre-edge features at 5993 and $5999 \mathrm{eV}$ visible in the derivative of the $\mu(\mathrm{E})$ spectrum [57]. EXAFS fits were not performed due to the difficulty of differentiating scattering by $\mathrm{Fe}$ and $\mathrm{Cr}$; the distortion of the immediate (hydr)oxide bonding environment as $\mathrm{Cr}$ is incorporated into increasingly crystalline solids is more easily detectable using XANES fitting [57]. The proportion of $\mathrm{Cr}$ (III) hydroxide in each fit varies between 0.54 and 0.66 . The proportions of each reference standard fit to the spectra have relatively high errors, but as the amount of $\mathrm{Cr}$ (III) hydroxide detected in each sample and the fitted values match the relative prominence of the characteristic $\mathrm{Cr}$ (III)-ferrihydrite features, errors in these values are unlikely to be as high as suggested by the fitting software. $\mathrm{Cr}$ (III)bearing ferrihydrite is the expected product of $\mathrm{Cr}(\mathrm{VI})$ reduction by $\mathrm{Fe}^{2+}{ }_{\text {(aq) }}$ under circumneutral conditions $[11,48,52]$; however, as differences in $\mathrm{Fe}^{2+}{ }_{(\mathrm{aq})}$ concentrations are minimal (Table 1), this likely has little effect on the speciation of $\mathrm{Cr}$ in the product. A portion of the green rust is also expected to dissolve when added to the chromate solutions due to the relatively high solubility of green rust, which likely affects the reactions performed in this study. However, as the initial $\mathrm{pH}$ values of the chromate solutions are identical, meaningful differences in the behavior of each batch reaction due to green rust dissolution are not expected, but possible. Cr speciation is correlated to the fraction of $\mathrm{Cr}$ (III) oxidizible by $\delta-\mathrm{MnO}_{2}$ after 14 days (Fig. 8b), but it is clear that oxMg-GR is an exception to the overall trend, as the fraction oxidized by $\delta-\mathrm{MnO}_{2}$ is lower than predicted. Therefore, it is likely that the low Cr lability in this product is the result of other factors such as partial conversion to feroxyhyte instead of depending purely on the Cr speciation.

Based on the XRD, PDF and XAS results, all oxidized samples appear to have maintained a layered structure composed of stacked SSI (Fig. 9) similar to those characterized by Yin et al. [56], with variable coherency and partial transformation to feroxyhyte in the case of oxMgGR. Following oxidation (regardless of mechanism), the resulting strain causes displacement of Fe(III) octahedra into an interlayer region labelled in Fig. 9 as the diffuse octahedral layer. Fe octahedral positions within this layer are not defined in a unit cell, as Fe displacements are random, but the uniform geometry of Fe octahedra ensures that the diffuse octahedral layer has a uniform thickness, allowing the particle to maintain its periodicity in the [001] direction. The actual basal plane spacings depend on the species present in the interlayer, including water. In the presence of sulfate, the original structure remains, as the (001) reflection is still visible in a diffraction pattern of the undried samples (Additional file 1: Figure

Table 4 Summary of Cr-XANES LCF fitting parameters

\begin{tabular}{|c|c|c|c|c|c|}
\hline Weighing factors & $\mathrm{Cr}(\mathrm{OH})_{3}$ & Cr-ferrihydrite & Sum & R-value & $\begin{array}{l}\text { Reduced } \\
\text { Chi } \\
\text { squared }\end{array}$ \\
\hline GR 7d & $0.62(4)$ & $0.40(4)$ & 1.02 & 0.003225 & 0.00202 \\
\hline AIGR 7d & $0.57(5)$ & $0.45(5)$ & 1.02 & 0.00584 & 0.00377 \\
\hline MgGR 7d & $0.54(5)$ & $0.45(5)$ & 0.99 & 0.00693 & 0.00418 \\
\hline ZnGR 7d & $0.66(3)$ & $0.36(3)$ & 1.02 & 0.00183 & 0.00116 \\
\hline
\end{tabular}



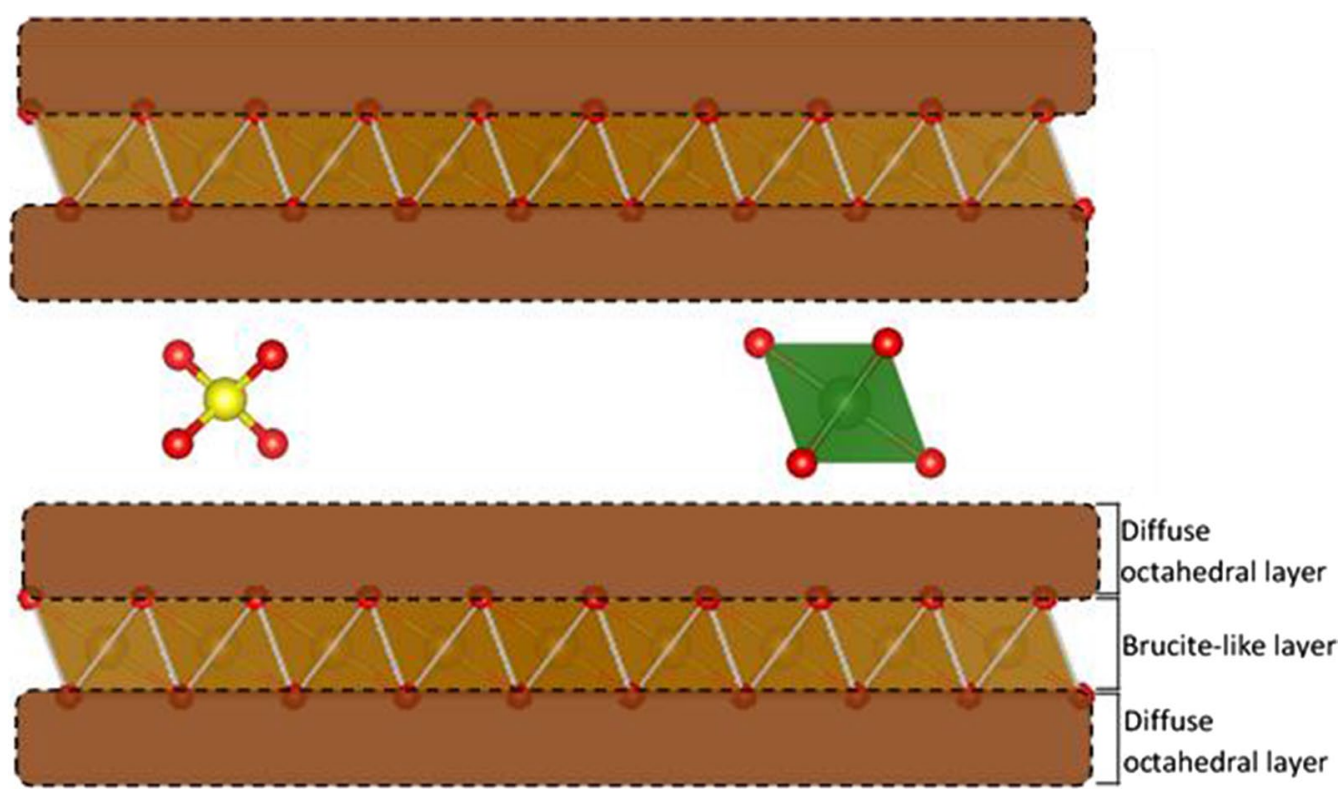

Fig. 9 Probable structure of the reaction product. The brucite-like layers present in green rust are preserved, but some octahedra are displaced into the diffuse octahedral layer. The interlayer spacing is determined by the presence of sulfate, water and hydrated $\mathrm{Cr}$ (III)

S1). However, displacement of Fe octahedra disrupts the hydrogen bonding in the basal layer that maintains the crystallographic coherence across layers, and as a result, many non-basal plane spacings are no longer detected or very faint in the diffraction patterns. These peaks in the XRD are broad, indicating poor coherence within the ab plane of the reaction products. In this case, linkage of adjacent layers and transformation to feroxyhyte is sterically inhibited by sulfate and the structure is better described as a metastable ferric green rust. However, if sulfate is removed by exchange for chromate prior to the $\mathrm{Fe}(\mathrm{II})-\mathrm{Cr}(\mathrm{VI})$ electron transfer, adjacent layers can be linked by either covalent bonding with $\mathrm{Cr}$ (III) or hydrogen bonding with residual $\mathrm{H}_{2} \mathrm{O}$; this can lead to the topotactic formation of other Fe oxides such as feroxyhyte. Feroxyhyte forms due to the linkage of adjacent layers, as the two phases have similar layered structures and hexagonal symmetries, so following linkage of two oxidized octahedral layers, only a slight reorganization is necessary for this transformation. This reaction mechanism was also proposed by Skovbjerg et al. [14] and our previous study [28], but appears to vary slightly depending on the initial chromium concentration, as higher concentrations favor chromate exchange for interlayer sulfate. The effects of initial chromium concentration on the substituted green rusts are unknown. In addition, the XRD patterns of some samples (oxMg-GR and oxGR, to a lesser extent) with higher non-basal plane crystallinity appear to have partially transformed to feroxyhyte, as characteristic feroxyhyte XRD peaks are visible in these diffraction patterns, although oxMg-GR is the only product in which this transformation is clear.

$\mathrm{Cr}$ (III) hydroxides are also present in the samples and may make a contribution to the PDF pattern between 0 and $10 \AA$, especially the correlations at 1.98 and $3.0 \AA$. A PDF pattern of $\mathrm{Cr}(\mathrm{III})$ hydroxide is not available; for peak positions and amplitudes, see Tang et al. [57]. Chromium reduced in the interlayer can form $\mathrm{Cr}(\mathrm{III})$ hydroxide domains $\left(\left[\mathrm{Cr}^{3+}\right]\right.$ is very high in the interlayer following reduction) or bind to adjacent diffuse octahedral layers. Interior $\mathrm{Cr}$ (III) hydroxide domains may have formed in oxMg-GR, as the low lability of $\mathrm{Cr}$ in this sample despite its relatively high $\mathrm{Cr}$ (III) hydroxide content suggests that this phase may be somehow sequestered. It should be noted that this is a metastable, transitional structure that will likely eventually transform to a mixture of $\mathrm{Cr}$ (III)bearing goethite and $\mathrm{Cr}(\mathrm{III})$ hydroxide.

\section{Effects of cation substitution on reaction mechanisms and byproducts}

Substitution of $\mathrm{Al}, \mathrm{Mg}$ and $\mathrm{Zn}$ for $\mathrm{Fe}$ in green rust sulfate alters the morphology, structure and chemical properties of the mineral $[36,37,59,60]$, which could result in substantial changes in reactivity and reaction mechanism when exposed to hexavalent chromium. Green rust [29], like magnetite and other Fe oxides [33], is a semiconductor, potentially allowing reduction of chromate at its surface and rims by electron transport from 
within the particle"s interior. Conduction within green rust is best modelled by a "polaron hopping" mechanism that transports electrons and electron holes in a series of of $\mathrm{Fe}(\mathrm{II})-\mathrm{Fe}(\mathrm{III})$ charge transfer steps rather than through a delocalized conduction band [29]. Density functional theory (DFT) modelling of polaron hopping within a green rust-like $\mathrm{Fe}(\mathrm{OH})_{2}$ plane showed that the potential rate of electron hole propagation at $300 \mathrm{~K}$ reaches $10^{10} \mathrm{~s}^{-1}$ in the case of transfer between nextnearest neighbor $\mathrm{FeO}_{6}$ octahedra (sites $\mathrm{Fe} 1$ and $\mathrm{Fe} 2$ in Fig. 10), $10^{8}$ times the rate of any other transfer mechanism. The most important parameter controlling the rate of charge transfer was the electronic coupling matrix element $\left(\mathrm{V}_{\mathrm{ab}}\right)$, which represents superexchange processes that link the electron spin states of magnetic cations (i.e. transmission metal cations with a net spin) covalently bound to a shared ligand $[35,61,62]$ as a consequence of the Pauli exclusion principle. This coupling mechanism allows $\mathrm{Fe}^{3+}$ ligand field transitions, which drive electron transfer and would otherwise be forbidden by the spinselection rule [33]. Next-nearest neighbor Fe atoms in green rust are not coupled directly by superexchange since they do not share a bridging $-\mathrm{OH}$ ligand, but are effectively coupled since both Fe octahedra participate in superexchange interactions with intermediate $\mathrm{Fe}(\mathrm{III})$ and $\mathrm{Fe}(\mathrm{II})$ octahedra (at sites $\mathrm{Me}^{3+}$ and $\mathrm{Me}^{2+}$ in Fig. 10). This rapid charge-hopping mechanism allows the regeneration of electron holes at the crystal edges resulting from chromate reduction and therefore continued reduction at the surface as long as it is not passivated. Oxidation by this mechanism would preserve the morphology and structure of the green rust, as it doesn't require exchange of chromate for sulfate. The continued presence of sulfate

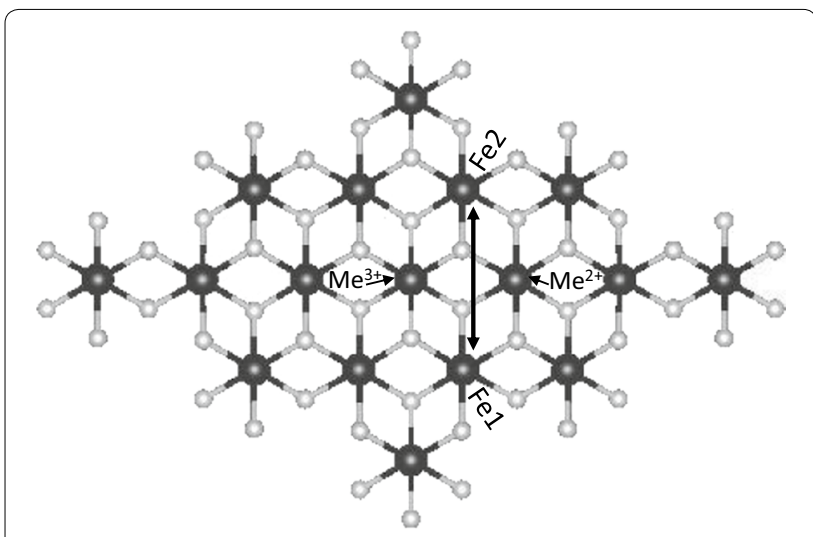

Fig. 10 Brucite-like sheet used to demonstrate electron transfer between Fe-centered octahedra. Electron transport is between next-nearest neighbor Fe sites labelled Fe1 and Fe2, which are coupled via superexchange with atoms at the neighboring sites $\mathrm{Me}^{2+}$ and $\mathrm{Me}^{3+}$ in the interlayer sterically inhibits linkages between adjacent layers but maintains the particle structure by linking adjacent layers via electrostatic interactions. Antony et al. [63] observed a reaction product with this structure when oxidizing green rust sulfate with $\mathrm{O}_{2}$, and our previous study [28] found a similar result. On the other hand, if chromate exchanges for sulfate and is reduced by nearby $\mathrm{Fe}(\mathrm{II})$, a new 3-dimensional structure can form as adjacent layers are linked. In this case, transformation to other Fe oxides such as feroxyhyte (as seen in the present study) or goethite [14] is possible.

Cation substitution is expected to alter this intrasheet conductivity, depending on the properties of the substituted cation. Since $\mathrm{Al}^{3+}, \mathrm{Mg}^{2+}$ and $\mathrm{Zn}^{2+}$ are not capable of donating or accepting electrons, as they do not have additional stable oxidation states, incorporation of these cations along the electron transfer chain at sufficient concentrations $(\geq 10 \%)$ can lower the rate of electron conduction to the particle surface [34, 64], and this effect may be stronger when electron transport is only possible in two dimensions. In addition, since these ions also have full or empty valence orbitals and therefore no net spin, they are unable to induce superexchange interactions with adjacent $\mathrm{FeO}_{6}$ octahedra when substituted at the $\mathrm{Me}^{2+}$ and $\mathrm{Me}^{3+}$ sites in Fig. 10 and therefore lower the rate of $\mathrm{Fe}(\mathrm{II}) \rightarrow \mathrm{Fe}(\mathrm{III})$ charge transfer. $\mathrm{Mg}$ substitution appears to have this effect, as the partial transformation to feroxyhyte, lower levels of $\mathrm{Cr}$ (III) hydroxide in the $\mathrm{Cr}$ K-edge XAS spectra and low $\mathrm{S}$ concentrations measured in oxMg-GR by EDX suggest that chromate exchange for sulfate is taking place during these reactions, which leads to the formation of a more stable product. Al-GR also produces a product more resistant to oxidation by $\delta-\mathrm{MnO}_{2}$ than pure green rust with a lower proportion of $\mathrm{Cr}$ (III) hydroxide. On the other hand, $\mathrm{Zn}$ substitution appears to have the opposite effect, as oxZn-GR was primarily composed of $\mathrm{Cr}$ (III) hydroxide and a layered, incoherently-stacked product as expected when $\mathrm{Cr}(\mathrm{VI})$ is reduced by electrons transferred to the crystal edges from its interior. As a non-magnetic cation, $\mathrm{Zn}^{2+}$ is also unable to couple the electron spin states of adjacent Fe-centered octahedra, and $\mathrm{Zn}$ substitution is expected to favor interlayer reduction of $\mathrm{Cr}(\mathrm{VI})$, and some evidence for this reaction exists in the form of the rim-like domains observed in the oxZn-GR TEM images. However, as $\mathrm{Cr}$ hydroxide is still the dominant $\mathrm{Cr}$ carrier phase in this sample, it is possible that other factors favor oxidative transformation of Zn-GR to a stacked SSI reaction product instead.

Additionally, cation substitution can lead to thermodynamic constraints on the reaction mechanism. For example, $\mathrm{Zn}^{2+}$ has a similar ionic radius to $\mathrm{Fe}^{2+}$ and is therefore easily incorporated at $\mathrm{Fe}(\mathrm{II})$ sites in green rust, 
phyllosilicates and other mixed-valence Fe oxides such as magnetite [65]. However, divalent metal substitution in $\mathrm{Fe}(\mathrm{III})$ (oxyhydr)oxides is generally not favorable because of its effects on the crystal field stabilization energy [66], differences in atomic radius, and effects on charge balance. Gerth [67] synthesized goethite with relatively high levels of $\mathrm{Zn}(\mathrm{Zn} / \mathrm{Zn}+\mathrm{Fe}=0.07)$, and Manceau et al. [68] identified natural goethite with approximately $2 \%$ substitution of $\mathrm{Zn}$ for $\mathrm{Fe}$, so $\mathrm{Zn}$ incorporation into a Fe (III) oxide product is possible but most likely not thermodynamically favorable in this system, particularly because $\mathrm{Zn}$ substitution at the $\mathrm{Fe}(\mathrm{II})$ site is so high (13.5\%). Instead, when ZnGR is oxidized by $\mathrm{Cr}(\mathrm{VI})$, the presence of a divalent cation with a higher ionic radius such as $\mathrm{Zn}^{2+}$ within the octahedral sheet may reduce the structural strain resulting from oxidation relative to other green rusts, possible including pure green rust sulfate. Therefore, the stacked SSI product is most likely more stable and crystalline, so chromate exchange for sulfate and collapse of the stacked SSI layers is less favorable. As a result, $\mathrm{Cr}(\mathrm{VI})$ reduction at the particle surface coupled to electron transfer from the interior is probably a more dominant reaction mechanism, producing $\mathrm{Cr}$ (III) hydroxide as the dominant $\mathrm{Cr}$ carrier phase in oxZn-GR.

\section{Conclusion}

Laboratory-scale experiments are only the first step in developing and implementing an effective in situ remediation method, but the results presented here suggest that the controlled substitution of cations into green rust can significantly improve its ability to remediate hexavalent chromium contamination. In particular, the increased stability of the reaction products in the case of Mg substitution represents a significant improvement compared to existing particle-based in situ chemical reduction methods, and the reactants can be simply and inexpensively synthesized from sulfate salts available in bulk as agricultural chemicals. $\mathrm{Mg}^{2+}$ is abundant in soils and non-toxic, and due to its similar ionic radius to $\mathrm{Fe}^{2+}(0.072 \mathrm{~nm}$ vs. $0.078 \mathrm{~nm}$, Shannon [69]), can easily substitute for structural $\mathrm{Fe}$ (II) and is a common substituent in green rusts identified in natural soils [37].

This technique is best applied by adding a large excess of ex situ-synthesized $\mathrm{Mg}$-substituted green rust to a Crcontaminated site. Excess Fe (III) allows the formation of more-crystalline $\mathrm{Fe}$ (III) oxides with lower levels of $\mathrm{Cr}$ incorporation [14], and excess Fe (II) can catalyze more rapid formation of these oxides [70-72] via a dissolutionprecipitation mechanism. These oxides may also be a sink for other metal contaminants often associated with chromium contamination at former metal plating sites such as $\mathrm{Ni}^{2+}, \mathrm{Cd}^{2+}$ and $\mathrm{Cu}^{2+}[3]$. In addition, under the reaction conditions tested in the present study $(\mathrm{pH}=7.0)$, the green rust surface is positively charged [73], which should favor sorption of chromate at the particle surface followed by reduction. Synthesizing green rust under more alkaline conditions $(\mathrm{pH}>8.0)$ may favor exchange of chromate for interlayer sulfate, as observed when reacting chromate with Fe (II)-bearing smectites [74, 75]. A study of these reactions at different initial chromium concentrations would also be useful for determining the reproducibility of these results under variable conditions. Finally, higher or lower levels of isomorphic substitution may also have an effect on the reactivities and reaction byproducts of these green rusts.

\section{Supplementary information}

Supplementary information accompanies this paper at https://doi. org/10.1186/s12932-020-00066-8.

Additional file 1. Includes $x$-ray diffraction patterns obtained using benchtop equipment as well as a more detailed description of the XAS data analysis procedure.

\section{Abbreviations}

ISCR: In situ chemical reduction; TEM: Transmission electron microscopy; XAS: X-ray absorption spectroscopy; XRD: X-ray diffraction; PDF: Pair distribution function; ICP-OES: Inductively-coupled plasma optical emission spectroscopy; FWHM: Full width half maximum; XANES: X-ray absorption near-edge spectroscopy; EXAFS: Extended X-ray absorption fine-structure spectroscopy; SEM: Scanning electron microscopy; EDX: Energy dispersive X-ray spectroscopy; SAED: Selected-area electron diffraction; STEM: Scanning transmission electron microscopy; DFT: Density functional theory; GR: Green rust; SSI:

Single-sheet iron oxided.

\section{Acknowledgements}

In addition, we would also like to acknowledge the synchrotron facility at the Angstromquelle Karlsruhe for providing resources for synchrotron-based absorption analyses, as well as the students and technical staff at the Institute of Applied Geosciences for their continued support. In particular, Gesine Preuss and Beate Oetzel at the Institute of Applied Geosciences assisted with ICP-OES and XRD measurements, respectively. Finally, Sandra Navaz Rubio for GFZ-Potsdam provided advice on interpretation of diffraction data.

\section{Authors' contributions}

AT designed and performed the study. EE, LB, DT and TN provided lab space and access to scientific instruments. JG and RS assisted with XAS measurements at the ANKA beamline. HF and MM performed electron microscopy and PDF measurements, respectively. KD assisted with interpretation of results and elucidation of the reaction mechanism. All authors assisted with writing the manuscript and approved its submission. All authors read and approved the final manuscript.

\section{Funding}

This project has received funding from the European Union's Horizon 2020 research and innovation programme under the Marie Skłodowska-Curie Grant Agreement No. 675219 and from the German Helmholtz Recruiting Initiative (Award Number I-044-16-0). This research also used resources at beamline SUL-X of the ANKA Synchrotron Facility and the Advanced Photon Source, a U.S. Department of Energy (DOE) Office of Science User Facility operated for the DOE Office of Science by Argonne National Laboratory under Contract No. DE-AC02-06CH11357.

\section{Availability of data and materials}

Data sets are available without restriction from the authors on request (andrew.thomas@kit.edu). 


\section{Competing interests}

The authors declare that they have no competing interests.

\section{Author details}

${ }^{1}$ Institute of Applied Geosciences, Karlsruhe Institute of Technology, 76137 Karlsruhe, Germany. ${ }^{2}$ Institute of Synchrotron Radiation, Karlsruhe Institute of Technology, 76344 Eggenstein-Leopoldshafen, Germany. ${ }^{3}$ GFZ German Research Center for Geosciences, Telegrafenberg, 14473 Potsdam, Germany. ${ }^{4}$ Department of Earth Sciences, Free University of Berlin, 12249 Berlin, Germany. ${ }^{5}$ Nano-Science Center, Department of Chemistry, University of Copenhagen, 2100 Copenhagen, Denmark. ${ }^{6}$ Department of Applied Geosciences, Technical University of Berlin, 10587 Berlin, Germany. ${ }^{7}$ Present Address: School of Chemical and Processing Engineering, University of Leeds, Leeds LS29JT, UK.

Received: 16 October 2019 Accepted: 4 February 2020 Published online: 14 February 2020

\section{References}

1. Puls RW, Paul CJ, Powell RM (1999) The application of in situ permeable reactive (zero-valent iron) barrier technology for the remediation of chromate-contaminated groundwater: a field test. Appl Geochem 14(8):989-1000

2. Ludwig RD, Su C, Lee TR, Wilkin RT, Acree SD, Ross RR et al (2007) In situ chemical reduction of $\mathrm{Cr}(\mathrm{VI})$ in groundwater using a combination of ferrous sulfate and sodium dithionite: a field investigation. Environ Sci Technol 41(15):5299-5305. https://doi.org/10.1021/es070025z

3. Saha R, Nandi R, Saha B (2011) Sources and toxicity of hexavalent chromium. J Coord Chem 64(10):1782-1806

4. Barceloux DG, Barceloux D (1999) Chromium. J Toxicol Clin Toxicol 37:173-194

5. Landrot G, Ginder-Vogel M, Livi K, Fitts JP, Sparks DL (2012) Chromium(III) oxidation by three poorly-crystalline manganese(IV) oxides. 1. Chromium(III)-oxidizing capacity. Environ Sci Technol 46(21):1159411600. https://doi.org/10.1021/es302383y

6. Bartlett R, James B (1979) Behavior of chromium in soils: Ill. Oxidation 1. J Environ Qual. 8(1):31

7. Hausladen DM, Fendorf S (2017) Hexavalent chromium generation within naturally structured soils and sediments. Environ Sci Technol 51(4):20582067. https://doi.org/10.1021/acs.est.6b04039

8. Pan C, Liu H, Catalano JG, Qian A, Wang Z, Giammar DE (2017) Rates of $\mathrm{Cr}(\mathrm{VI})$ generation from $\mathrm{Cr} \times \mathrm{Fe} 1-\mathrm{x}(\mathrm{OH}) 3$ solids upon reaction with manganese oxide. Environ Sci Technol 51(21):12416-12423. https://doi. org/10.1021/acs.est.7b04097

9. Varadharajan C, Beller HR, Bill M, Brodie EL, Conrad ME, Han R et al (2017) Reoxidation of chromium(III) products formed under different biogeochemical regimes. Environ Sci Technol 51(9):4918-4927. https://doi. org/10.1021/acs.est.6b06044

10. Rai D, Sass BM, Moore DA (1987) Chromium(III) hydrolysis constants and solubility of chromium(III) hydroxide. ChemInform. https://doi. org/10.1002/chin.198720020

11. Papassiopi N, Vaxevanidou K, Christou C, Karagianni E, Antipas GSE (2014) Synthesis, characterization and stability of $\mathrm{Cr}(\mathrm{III})$ and $\mathrm{Fe}(\mathrm{III})$ hydroxides. J Hazard Mater 264:490-497

12. Christiansen BC, Dideriksen K, Katz A, Nedel S, Bovet N, Sørensen HO et al (2014) Incorporation of monovalent cations in sulfate green rust. Inorg Chem 53(17):8887-8894. https://doi.org/10.1021/ic500495a

13. Bond DL, Fendorf S (2003) Kinetics and structural constraints of chromate reduction by green rusts. Environ Sci Technol 37(12):2750-2757. https:// doi.org/10.1021/es026341p

14. Skovbjerg LL, Stipp SLS, Utsunomiya S, Ewing RC (2006) The mechanisms of reduction of hexavalent chromium by green rust sodium sulphate: formation of Cr-goethite. Geochim Cosmochim Acta 70(14):3582-3592

15. O'Loughlin EJ, Kelly SD, Cook RE, Csencsits R, Kemner KM (2003) Reduction of uranium(VI) by mixed iron(II)/iron(III) hydroxide (green rust): formation of UO 2 nanoparticles. Environ Sci Technol 37(4):721-727. https ://doi.org/10.1021/es0208409
16. Jönsson J, Sherman DM (2008) Sorption of As(III) and As(V) to siderite, green rust (fougerite) and magnetite: implications for arsenic release in anoxic groundwaters. Chem Geol 255(1-2):173-181

17. Perez JPH, Freeman HM, Schuessler JA, Benning LG (2019) The interfacial reactivity of arsenic species with green rust sulfate (GRSO4). Sci Total Environ 648:1161-1170

18. Hansen HCB, Koch CB (1998) Reduction of nitrate to ammonium by sulphate green rust: activation energy and reaction mechanism. Clay Miner 33(01):87-101

19. Hansen HCB, Guldberg S, Erbs M, Bender Koch C (2001) Kinetics of nitrate reduction by green rusts-effects of interlayer anion and Fe(II):Fe(III) ratio. Appl Clay Sci 18(1-2):81-91

20. Latta D, Boyanov M, Kemner K, O'Loughlin E, Scherer M (2015) Reaction of uranium( $\mathrm{VI})$ with green rusts: effect of interlayer anion. Curr Inorg Chem. 5(3):156-168

21. Myneni SC (1997) Abiotic selenium redox transformations in the presence of Fe(II, III) oxides. Science (80-) 278(5340):1106-1109. https://doi. org/10.1126/science.278.5340.1106

22. Refait P, Simon L, Génin JMR (2000) Reduction of SeO42- anions and anoxic formation of iron(II)-Iron(III) hydroxy-selenate green rust. Environ Sci Technol 34(5):819-825

23. Christiansen BC, Geckeis H, Marquardt CM, Bauer A, Römer J, Wiss T et al (2011) Neptunyl (NpO2) interaction with green rust. Geochim Cosmochim Acta 75(5):1216-1226

24. Loyaux-Lawniczak S, Refait P, Lecomte C, Ehrhardt J, Genin JR (1999) The reduction of chromate ions by Fe (II) layered hydroxides. Hydrol Earth Syst Sci 3:593-599

25. Loyaux-Lawniczak S, Refait P, Ehrhardt JJ, Lecomte P, Génin JMR (2000) Trapping of $\mathrm{Cr}$ by formation of ferrihydrite during the reduction of chromate ions by Fe(II)-Fe(III) hydroxysalt green rusts. Environ Sci Technol. 34(3):438-443. https://doi.org/10.1021/es9903779

26. Williams AGB, Scherer MM (2001) Kinetics of $\mathrm{Cr}(\mathrm{VI})$ Reduction by Carbonate Green Rust. Environ Sci Technol. 35(17):3488-3494. https://doi. org/10.1021/es010579g

27. Legrand L, El Figuigui A, Mercier F, Chausse A (2004) Reduction of aqueous chromate by $\mathrm{Fe}(\mathrm{II}) / \mathrm{Fe}(\mathrm{III})$ carbonate green rust: kinetic and mechanistic studies. Environ Sci Technol 38(17):4587-4595. https://doi. org/10.1021/es035447x

28. Thomas A, Eiche E, Göttlicher J, Steininger R, Benning LG, Freeman HM et al (2018) Products of hexavalent chromium reduction by green rust sodium sulfate and associated reaction mechanisms. Soil Syst. 2(4):58

29. Wander MCF, Rosso KM, Schoonen MAA (2007) Structure and charge hopping dynamics in green rust. J Phys Chem C 111(30):11414-11423. https://doi.org/10.1021/jp072762n

30. Alexandrov AS, Mott NF. Polarons and Bipolarons. World Scientific; 1996 https://www.worldscientific.com/worldscibooks/10.1142/2784

31. Ederth J, Hoel A, Niklasson GA, Granqvist CG (2004) Small polaron formation in porous WO3-x nanoparticle films. J Appl Phys 96(10):5722-5726. https://doi.org/10.1063/1.1804617

32. Katz JE, Zhang X, Attenkofer K, Chapman KW, Frandsen C, Zarzycki P et al (2012) Electron small polarons and their mobility in iron (oxyhydr) oxide nanoparticles. Science (80-) 337(6099):1200-1203. https://doi. org/10.1126/science 1223598

33. Sherman DM. Crystal chemistry, electronic structures, and spectra of fe sites in clay minerals: applications to photochemistry and electron transport. In: Coyne LM, McKeever SWS, Blake DF, editors. Spectroscopic characterization of minerals and their surfaces. Washington, DC: American Chemical Society; 1990. p. 284-309. (ACS Symposium Series; vol. 415). http://pubs.acs.org/doi/book/10.1021/bk-1990-0415

34. Alexandrov $\vee$, Rosso KM (2014) Electron transport in pure and substituted iron oxyhydroxides by small-polaron migration. J Chem Phys. https://doi. org/10.1063/1.4882065

35. Kanamori J (1959) Superexchange interaction and symmetry properties of electron orbitals. J Phys Chem Solids 10(2-3):87-98

36. Ruby C, Abdelmoula M, Aissa R, Medjahdi G, Brunelli M, François M (2008) Aluminium substitution in iron(II-III)-layered double hydroxides: formation and cationic order. J Solid State Chem 181(9):2285-2291

37. Refait P, Abdelmoula M, Trolard F, Génin JMR, Bourkié G (2001) Mössbauer and XAS study of a green rust mineral; the partial substitution of Fe2+ by Mg2+. Am Mineral 86(5-6):731-739 
38. Ahmed IAM, Shaw S, Benning LG (2008) Formation of hydroxysulphate and hydroxycarbonate green rusts in the presence of zinc using timeresolved in situ small and wide angle $X$-ray scattering. Mineral Mag 72(1):159-162

39. Géhin A, Ruby C, Abdelmoula M, Benali O, Ghanbaja J, Refait P et al (2002) Synthesis of Fe(II-III) hydroxysulphate green rust by coprecipitation. Solid State Sci 4(1):61-66

40. Gibbs CR (1976) Characterization and application of FerroZine iron reagent as a ferrous iron indicator. Anal Chem 48(8):1197-1201. https://doi. org/10.1021/ac50002a034

41. Carlson L, Schwertmann U (1980) Natural occurrence of feroxyhite $\left(\delta^{\prime}-\mathrm{FeOOH}\right)$. Clays Clay Miner 28(4):272-280

42. Villalobos M, Lanson B, Manceau A, Toner B, Sposito G (2006) Structural model for the biogenic Mn oxide produced by Pseudomonas putida. Am Mineral 91(4):489-502

43. Villalobos M, Toner B, Bargar J, Sposito G (2003) Characterization of the manganese oxide produced by Pseudomonas putida strain MnB1. Geochim Cosmochim Acta 67(14):2649-2662

44. Toby BH, Von Dreele RB (2013) GSAS-II : the genesis of a modern opensource all purpose crystallography software package. J Appl Crystallogr 46(2):544-549

45. Juhás P, Davis T, Farrow CL, Billinge SJL (2013) PDFgetX3: a rapid and highly automatable program for processing powder diffraction data into total scattering pair distribution functions. J Appl Crystallogr 46(2):560-566

46. Egami T, Billinge SJL (2012) Underneath the Bragg peaks: structural analysis of complex materials, 2nd edn. Elsevier, Oxford

47. Ravel B, Newville M (2005) ATHENA and ARTEMIS interactive graphical data analysis using IFEFFIT. Phys Scr T115:1007-1010

48. Papassiopi N, Pinakidou F, Katsikini M, Antipas GSE, Christou C, Xenidis A et al (2014) A XAFS study of plain and composite iron (III) and chromium (III) hydroxides. Chemosphere 111:169-176

49. Schwertmann U, Cornell RM (2008) Iron oxides in the laboratory, 2nd edition, 2nd edn. Wiley-WCH, Weinheim

50. Manceau A, Drits VA (1993) Local structure of ferrihydrite and feroxyhyte by EXAFS spectroscopy. Clay Miner 28(02):165-184

51. Blake RL, Hessevick RE, Zoltai T, Finger LW (1966) Refinement of the hematite structure. Am Mineral 51(1-2):123-129

52. Buerge IJ, Hug SJ (1997) Kinetics and pH dependence of chromium (VI) reduction by iron (II). Environ Sci Technol. 31(5):1426-1432. https://doi. org/10.1021/es960672i

53. Simon L, François M, Refait P, Renaudin G, Lelaurain M, Génin JMR (2003) Structure of the Fe(II-III) layered double hydroxysulphate green rust two from Rietveld analysis. Solid State Sci 5(2):327-334

54. Patrat G, de Bergevin F, Pernet M, Joubert JC (1983) Structure locale de

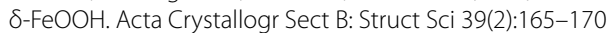

55. Michel FM, Ehm L, Antao SM, Lee PL, Chupas PJ, Liu G et al (2007) The structure of ferrihydrite, a nanocrystalline material. Science (80-) 316(5832):1726-1729. https://doi.org/10.1126/science.1142525

56. Yin Z, Dideriksen K, Abdelmoula M, Ruby C, Michel FM, Bjerrum MJ et al (2019) Structure of single sheet iron oxides produced from surfactant interlayered green rusts. Appl Clay Sci 170:86-96

57. Tang Y, Michel FM, Zhang L, Harrington R, Parise JB, Reeder RJ (2010) Structural properties of the $\mathrm{Cr}(\mathrm{III})$ - Fe(III) (Oxy)hydroxide compositional series: insights for a nanomaterial "solid solution". Chem Mater 22(12):3589-3598. https://doi.org/10.1021/cm1000472

58. Drits VA, Sakharov BA, Manceau A (1993) Structure of feroxyhite as determined by simulation of X-ray diffraction curves. Clay Miner 28(2):209-222

59. Refait P, Sabot R, Jeannin M (2017) Role of $\mathrm{Al}(\mathrm{III})$ and $\mathrm{Cr}(\mathrm{III})$ on the formation and oxidation of the Fe(II-III) hydroxysulfate green rust. Colloids Surfaces A Physicochem Eng Asp 531:203-212. https://doi.org/10.1016/j. colsurfa.2017.08.006
60. Zhang H, Wen X, Wang Y (2007) Synthesis and characterization of sulfate and dodecylbenzenesulfonate intercalated zinc-iron layered double hydroxides by one-step coprecipitation route. J Solid State Chem 180(5):1636-1647

61. Goodenough JB (1955) Theory of the role of covalence in the perovskitetype manganites [La, M(II)] $\mathrm{MnO}_{3}$. Phys Rev 100(2):564-573. https://doi. org/10.1103/PhysRev.100.564

62. Goodenough JB (1958) An interpretation of the magnetic properties of the perovskite-type mixed crystals La $1-x \mathrm{SrxCoO} 3-\lambda$. J Phys Chem Solids 6(2-3):287-297

63. Antony $H$, Legrand L, Chaussé A (2008) Carbonate and sulphate green rusts - mechanisms of oxidation and reduction. Electrochim Acta 53(24):7146-7156

64. Latta DE, Bachman JE, Scherer MM (2012) Fe Electron transfer and atom exchange in goethite: influence of Al-substitution and anion sorption. Environ Sci Technol 46(19):10614-10623. https://doi.org/10.1021/es302 094a

65. Sidhu PS, Gilkes RJ, Posner AM (1978) The synthesis and some properties of Co, Ni, Zn, Cu, Mn and Cd substituted magnetites. J Inorg Nucl Chem 40(3):429-435

66. Dawson BSW, Fergusson JE, Campbell AS, Cutler EJB (1985) Distribution of elements in some Fe-Mn nodules and an iron-pan in some gley soils of New Zealand. Geoderma 35(2):127-143

67. Gerth J (1990) Unit-cell dimensions of pure and trace metal-associated goethites. Geochim Cosmochim Acta 54(2):363-371

68. Manceau A, Schlegel ML, Musso M, Sole VA, Gauthier C, Petit PE et al (2000) Crystal chemistry of trace elements in natural and synthetic goethite. Geochim Cosmochim Acta 64(21):3643-3661

69. Shannon RD (1976) Revised effective ionic radii and systematic studies of interatomic distances in halides and chalcogenides. Acta Crystallogr Sect A. 32(5):751-767

70. Boland DD, Collins RN, Miller CJ, Glover CJ, Waite TD (2014) Effect of solution and solid-phase conditions on the Fe(II)-accelerated transformation of ferrihydrite to lepidocrocite and goethite. Environ Sci Technol 48(10):5477-5485. https://doi.org/10.1021/es4043275

71. Yang L, Steefel Cl, Marcus MA, Bargar JR (2010) Kinetics of Fe(II)-catalyzed transformation of 6-line ferrihydrite under anaerobic flow conditions. Environ Sci Technol. 44(14):5469-5475. https://doi.org/10.1021/es100 7565

72. Pedersen HD, Postma D, Jakobsen $R$, Larsen $O$ (2005) Fast transformation of iron oxyhydroxides by the catalytic action of aqueous Fe (II). Geochim Cosmochim Acta 69(16):3967-3977

73. Guilbaud R, White ML, Poulton SW (2013) Surface charge and growth of sulphate and carbonate green rust in aqueous media. Geochim Cosmochim Acta. 108:141-153. https://doi.org/10.1016/j.gca.2013.01.017

74. Bishop ME, Dong H, Glasser P, Briggs BR, Pentrak M, Stucki JW et al (2019) Reactivity of redox cycled Fe-bearing subsurface sediments towards hexavalent chromium reduction. Geochim Cosmochim Acta. 252:88-106. https://doi.org/10.1016/j.gca.2019.02.039

75. Bishop ME, Glasser P, Dong H, Arey B, Kovarik L (2014) Reduction and immobilization of hexavalent chromium by microbially reduced Febearing clay minerals. Geochim Cosmochim Acta. 133:186-203. https:// doi.org/10.1016/j.gca.2014.02.040

\section{Publisher's Note}

Springer Nature remains neutral with regard to jurisdictional claims in published maps and institutional affiliations. 